ROBERTA FERRARI MARBACK

\title{
Cirurgia de catarata: opiniões, expectativas e reações emocionais de pacientes com visão mono versus binocular
}

Tese apresentada à Faculdade de Medicina da Universidade de São Paulo para obtenção do título de Doutor em Ciências

Área de concentração: Oftalmologia

Orientador: Dr. Newton Kara José Júnior

São Paulo 
Dados Internacionais de Catalogação na Publicação (CIP)

Preparada pela Biblioteca da

Faculdade de Medicina da Universidade de São Paulo

Creprodução autorizada pelo autor

Marback, Roberta Ferrari

Cirurgia de catarata : opiniões, expectativas e reações emocionais de pacientes com visão mono versus binocular / Roberta Ferrari Marback. -- São Paulo, 2007.

Tese(doutorado)--Faculdade de Medicina da Universidade de São Paulo.

Departamento de Oftalmologia e Otorrinolaringologia.

Área de concentração: Oftalmologia.

Orientador: Newton Kara José Júnior.

Descritores: 1.Extração de catarata 2.Visão monocular 3.Visão binocular 4.Acuidade visual 5.Psicologia 6.Saúde pública

USP/FM/SBD-403/07 
"Quero dizer agora o oposto do que eu disse antes

Eu prefiro ser essa metamorfose ambulante Do que ter aquela velha opinião formada sobre tudo..." Raul Seixas 
Dedicatória 
Aos meus pais, Roberto e Marina, com muito amor, carinho e admiração, que sempre acreditaram em mim e estiveram ao meu lado, incentivando e me fazendo crescer, nos momentos de queda, me ensinaram a levantar e seguir em frente. Esta tese é de vocês!

Aos meus irmãos Heitor e Eduardo, meus sobrinhos, Bíu, Juju e Lipe, e minhas cunhadas Cinara e Patrícia, pelo amor e carinho dispensados. Desculpem a ausência durante todo esse tempo, estarei de volta em breve! Saudades... 
Ao Prof. Dr. Newton Kara José, pessoa admirável, exemplo de professor, sempre dedicado aos seus alunos e, na busca incansável pela prevenção da cegueira, me fez enxergar a preciosidade da pesquisa científica. Muito obrigada pelas inúmeras horas dispensadas ao aperfeiçoamento desta tese. Grata pela grandiosa oportunidade e confiança no meu estudo. 
Agradecimentos 
Ao Dr. Newton Kara-Júnior, meu orientador, pela amizade, por partilhar seu tempo e saber, sempre em busca do aprimoramento deste estudo, com valiosas orientações.

À Profa. Dra. Edméa Rita Temporini Nastari, pela amizade, disponibilidade e por ter me acompanhado desde os primeiros passos no terreno da pesquisa científica, com preciosos ensinamentos e, durante a confecção deste estudo, com sugestões e correções sempre pertinentes. Obrigada por tudo!

Ao Prof. Dr. Mário Luiz Ribeiro Monteiro, pela credibilidade depositada nesta pesquisa e pelas sugestões oferecidas.

Ao Prof. Dr. Euclides Ayres de Castilho, pela amizade e disponibilidade sempre que solicitado.

À Dra. Regina de Souza Carvalho, pela amizade, incentivo e indicações bibliográficas, que muito contribuíram na elaboração desta pesquisa.

Aos Drs. Marcos Wilson Sampaio e José Antônio de Almeida Milani, pelas contribuições apontadas a partir da leitura deste estudo.

Aos colegas do Curso de Pós-Graduação e estagiários do Setor de Catarata, pelo agradável convívio. 
À Regina Ferreira de Almeida, pela sua competência, pelos conselhos e carinho recebidos.

À Cléia Borges Gomes, pela amizade e por sempre estar disposta a ajudar no que fosse preciso.

Aos funcionários do Setor de Oftalmologia, pelo agradável ambiente de trabalho.

À Creusa Maria Roveri Dal Bó, pela minuciosa análise estatística.

Aos pacientes, pela grandiosa colaboração, sem eles esse estudo não existiria. Fizeram-me enxergar, com visão binocular, a importância do estudo de fatores humanos na saúde ocular.

À CAPES (Coordenação de Aperfeiçoamento de Pessoal de Nível Superior), por apoiar financeiramente essa pesquisa.

À minha querida tia Anna Amélia Marback Barbosa de Souza, pelo carinho e atenção sempre dispensados e pela correção lingüística deste estudo.

Ao Otacílio Maia Júnior, meu amor, pelo carinho, pelas palavras nas horas certas e por estar sempre ao meu lado, sua presença foi fundamental na elaboração deste trabalho. Essa vitória também é sua! 
À Goretti Maia e Charles Ribeiro, pelo carinho, pela torcida e pela companhia durante todos esses anos longe de casa. Valeu!
À Cláudia Dias Macêdo, Grace Milene Souza Andrade e Lia Paula Miranda Aguiar, amigas sempre presentes. Obrigada por tudo!
E a todos que fazem parte da minha vida e, direta ou indiretamente contribuíram para a realização deste estudo, minha eterna gratidão. 


\section{NORMALIZAÇÃO ADOTADA}

Esta tese está de acordo com as seguintes normas, em vigor no momento desta publicação:

Referências: adaptado de International Committee of Medical Journals Editors (Vancouver)

Universidade de São Paulo. Faculdade de Medicina. Serviço de Biblioteca e Documentação. Guia de apresentação de dissertações, teses e monografias. Elaborado por Anneliese Carneiro da Cunha, Maria Júlia de A. L. Freddi, Maria F. Crestana, Marinalva de Souza Aragão, Suely Campos Cardoso, Valéria Vilhena. $2^{a}$ ed. São Paulo: Serviço de Biblioteca e Documentação; 2005.

Abreviaturas dos títulos dos periódicos de acordo com List of Journals Indexed in Index Medicus. 
Sumário 
Lista de abreviaturas, siglas e símbolos ......................................... xvi

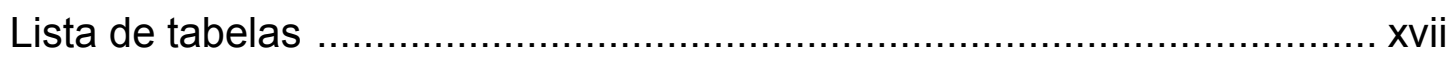

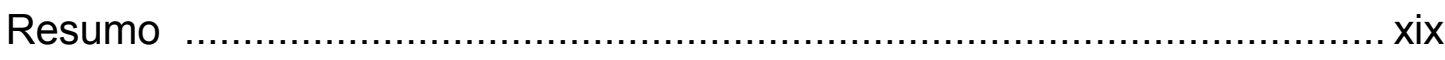

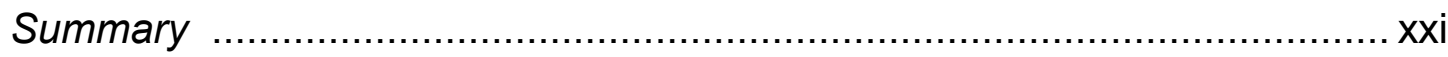

1. INTRODUÇÃO ….......................................................................... 1

1.1 Cegueira - Definição e Situação Mundial...................................... 2

1.2 Cegueira por catarata no mundo ......................................... 4

1.3 Cegueira por catarata no Brasil e ações preventivas …................. 8

1.4 A evolução da cirurgia de catarata .........................................12

1.5 Baixa Visão .................................................................... 15

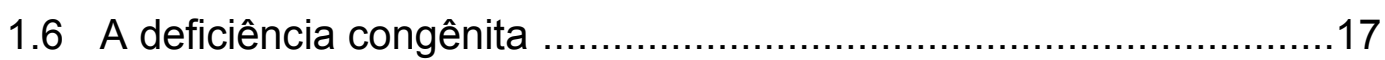

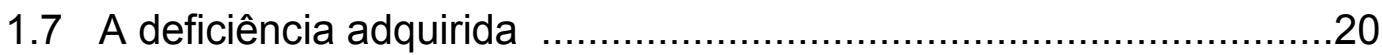

1.8 Reações emocionais de pacientes com indicação cirúrgica ............26

1.9 Reações emocionais de pacientes com indicação cirúrgica de

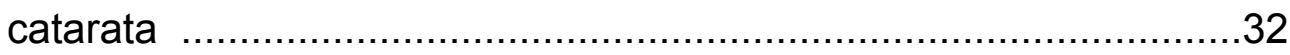

1.10 O paciente com visão monocular ..........................................35

1.11 Fatores humanos relacionados à cirurgia de catarata .................36

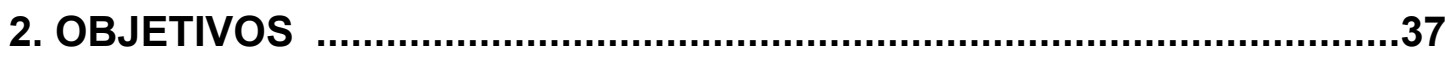

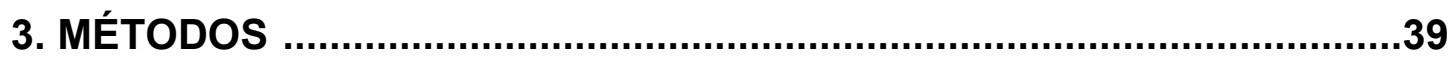

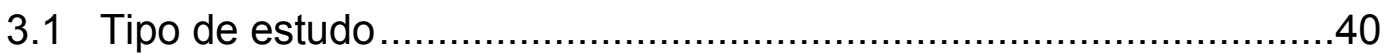

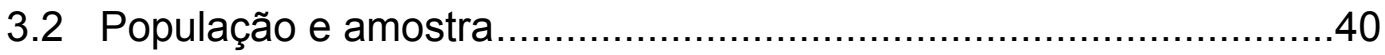

3.3 Critérios de inclusão e exclusão .............................................42

3.4 Variáveis........................................................................ 44

3.4.1 Variáveis dependentes ...........................................44

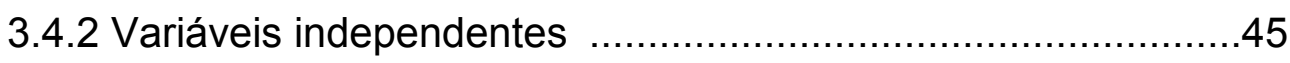

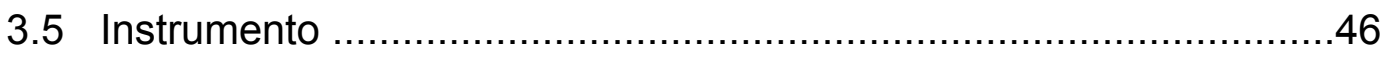

3.5.1 Estudo exploratório ....................................................46

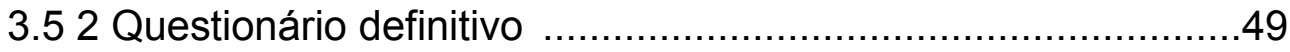

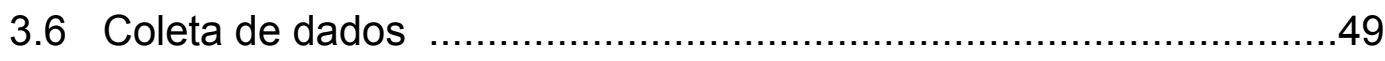

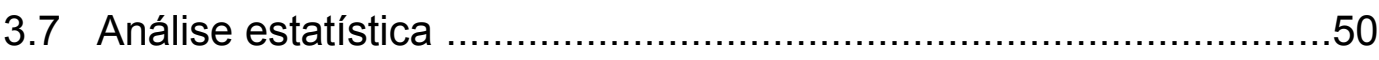


3.8 Processamento dos dados .............................................. 51

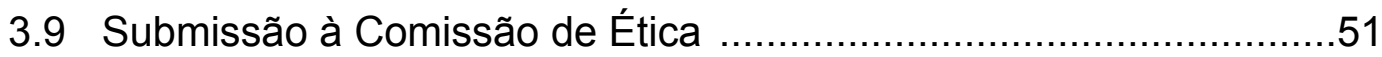

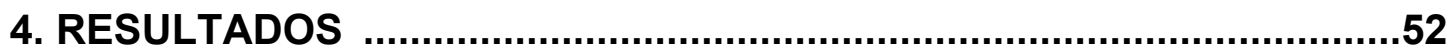

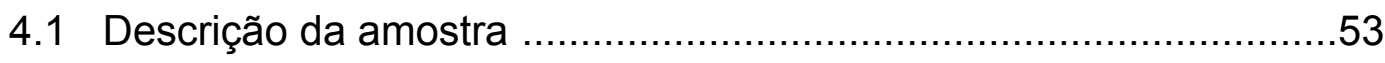

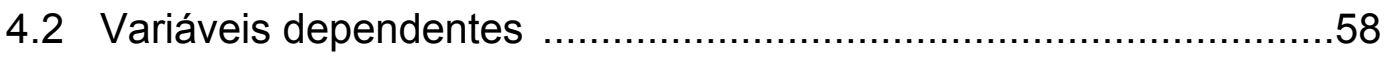

4.2.1 Opiniões, expectativas e reações emocionais ......................58

4.3 Resultados analíticos ............................................................69

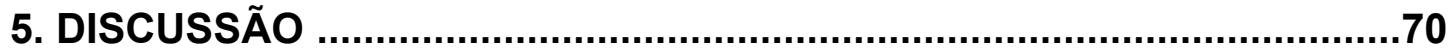

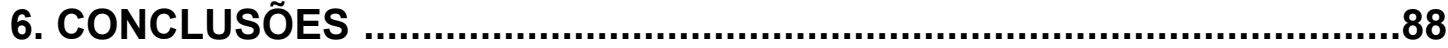

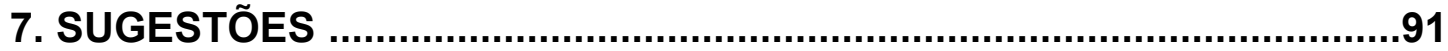

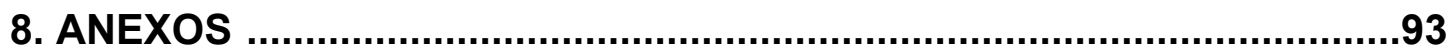

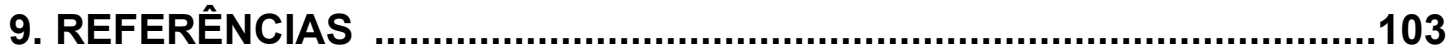


Listas 


\section{Lista de Abreviaturas, Siglas e Símbolos}

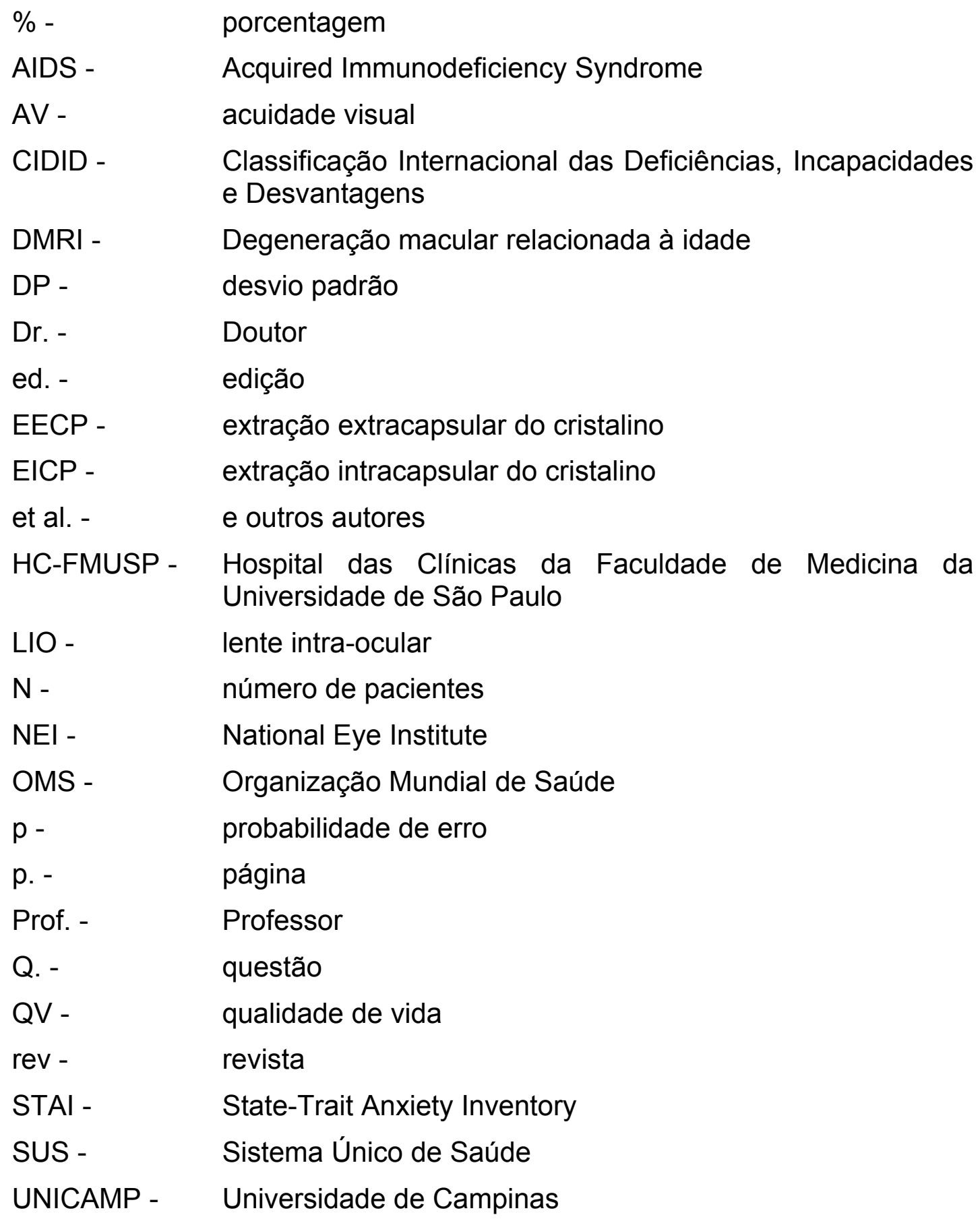




\section{Lista de Tabelas}

Tabela 1 - Características pessoais de pacientes com visão monocular (grupo 1) e com visão binocular (grupo 2), a serem submetidos à cirurgia de catarata. HC-FMUSP 2007

Tabela 2 - Situação ocupacional de pacientes com visão monocular (grupo 1) e com visão binocular (grupo 2), a serem submetidos à cirurgia de catarata. HC-FMUSP - 2007

Tabela 3 - Acuidade visual do olho a ser operado e do olho contralateral. Pacientes com visão monocular (grupo 1) e com visão binocular (grupo 2), a serem submetidos à cirurgia de catarata. HC-FMUSP - 2007

Tabela 4 - Opinião referente ao tempo decorrido e à causa da perda visual do olho cego e diagnóstico médico. Pacientes com visão monocular, a serem submetidos à cirurgia de catarata (grupo 1). HC-FMUSP - 2007

Tabela 5 - Expectativas quanto às possibilidades de mudanças na qualidade de vida, caso perdesse a visão monocular. Pacientes com visão monocular (grupo 1), a serem submetidos à cirurgia de catarata. HC-FMUSP - 2007

Tabela 6 - Opinião quanto à dificuldade visual para realizar as atividades da vida diária. Pacientes com visão monocular (grupo 1) e com visão binocular (grupo 2), a serem submetidos à cirurgia de catarata. HC-FMUSP - 2007 
Tabela 7 - Opinião sobre a qualidade da visão e sobre a causa da perda visual. Pacientes com visão monocular (grupo 1) e com visão binocular (grupo 2), a serem submetidos à cirurgia de catarata. HC-FMUSP - 2007

Tabela 8 - Opinião referente a grau e causa do medo de pacientes com visão monocular (grupo 1) e com visão binocular (grupo 2), a serem submetidos à cirurgia de catarata. HC-FMUSP - 2007

Tabela 9 - Sentimentos manifestados por pacientes com visão monocular (grupo 1) e com visão binocular (grupo 2), a serem submetidos à cirurgia de catarata. HC-FMUSP _ 2007 (Respostas afirmativas e múltiplas)

Tabela 10 - Expectativa quanto à possibilidade de melhora do estilo de vida de pacientes com visão monocular (grupo 1) e com visão binocular (grupo 2), a serem submetidos à cirurgia de catarata. HC-FMUSP - 2007

Tabela 11 - Expectativas quanto à realização de atividades após a cirurgia da catarata. Pacientes com visão monocular (grupo 1) e com visão binocular (grupo 2), a serem submetidos à cirurgia de catarata. HC-FMUSP - 2007 (Respostas múltiplas)

Tabela 12 - Sentimento de dúvida quanto a ter bom resultado na cirurgia de pacientes com visão monocular (grupo 1) comparado com pacientes com visão binocular (grupo 2), a serem submetidos à cirurgia de catarata. HC-FMUSP 2007 
Resumo 
Marback RF. Cirurgia de catarata: opiniões, expectativas e reações emocionais de pacientes com visão mono versus binocular [tese]. São Paulo: Faculdade de Medicina, Universidade de São Paulo; 2007. 121 p.

O estudo teve como objetivos verificar em dois grupos de pacientes com visão monocular (grupo 1) e com visão binocular (grupo 2), a serem submetidos à cirurgia de catarata no Hospital das Clínicas da Faculdade de Medicina da Universidade de São Paulo, opiniões, expectativas e reações emocionais em relação ao problema ocular, à qualidade da visão e à cirurgia de catarata; influência da característica de apresentar visão mono ou binocular nas reações emocionais relacionadas à cirurgia de catarata. Foi realizado estudo transversal e comparativo, de forma consecutiva, por meio de questionário estruturado, aplicado por entrevista a pacientes, elaborado a partir de estudo exploratório e medidas acuidade visual e causa da perda visual. A amostra foi constituída por 96 indivíduos do grupo 1 (50,0\% homens; $50,0 \%$ mulheres, com idade entre 41 e 91 anos, média 69,3 anos $\pm 10,4$ anos) e 110, do grupo 2 (40,9\% homens; 59,1\% mulheres, com idade entre 40 e 89 anos, média 68,2 anos $\pm 10,2$ anos). A maioria dos indivíduos de ambos os grupos apresentava baixa escolaridade. Não houve diferença estatisticamente significante entre os grupos em relação ao sexo $(p=0,191)$, à idade $(p=0,702)$ e à escolaridade $(p=$ 0,245 ). Não exerciam atividade laboral $95,8 \%$ dos indivíduos do grupo 1 e $83,6 \%$, do grupo 2 ( $p=0,005)$ e $30,4 \%$ do grupo 1 mencionaram não ter possibilidade de trabalhar por causa da deficiência visual. Observou-se acuidade visual do olho a ser operado menor que 0,05 em 40,6\% (grupo 1) e 33,6\% (grupo 2), entre 0,25 e 0,05. Quase a totalidade dos indivíduos de ambos os grupos afirmou ter dificuldade para realização das atividades de vida diária e qualificou como insuficiente a respectiva acuidade visual; $71,9 \%$ dos entrevistados do grupo 1 e $71,6 \%$, do grupo 2 mencionaram saber a causa da visão fraca; desses, $87,1 \%$ do grupo 1 e $83,3 \%$ do grupo 2 referiram a catarata como causa da baixa acuidade visual. No que se refere ao medo, $40,6 \%$ dos indivíduos do grupo 1 e $22,7 \%$, do grupo 2 , relataram ter medo do procedimento cirúrgico $(p=0,009)$. As causas de medo mais referidas foram: possibilidade de perder a visão; piorar a visão; sofrer alguma complicação na cirurgia; morrer durante a cirurgia. Os sentimentos mais preponderantes entre os grupos foram: satisfação por saber que a catarata pode ser operada e melhorar a visão, alívio por saber que vai ser operado, dúvida quanto a ter bom resultado, nervosismo. Referiram esperar que mudanças ocorressem na vida após a cirurgia $90,6 \%$ (grupo 1) e $84,6 \%$ (grupo 2). Quanto às atividades que esperavam realizar após a cirurgia mencionaram: realizar serviços de casa; ler; sair sozinho. Concluiuse que: os indivíduos de ambos os grupos tiveram acesso à cirurgia de catarata com acuidade visual menor do que a idealmente indicada; os pacientes com visão monocular apresentaram acuidade visual significativamente menor em relação aos com visão binocular; a maioria dos entrevistados de ambos os grupos referiu dificuldades para realizar atividades cotidianas como conseqüência da baixa visão; os indivíduos com visão monocular referiram mais dúvida em relação aos resultados cirúrgicos do que os com visão binocular; muitos indivíduos de ambos os grupos desconheciam a causa da dificuldade visual ou a atribuíram a outra causa que não a catarata; indivíduos de ambos os grupos apontaram expectativas positivas em relação à reabilitação após a cirurgia.

Descritores: Cirurgia de catarata; Visão Monocular; Visão Binocular; Acuidade Visual; Psicologia; Saúde Pública. 
Marback RF. Cataract surgery: opinions, expectances and emotional reactions of patients with monocular versus binocular vision [thesis]. São Paulo: "Faculdade de Medicina, Universidade de São Paulo"; 2007. 121p.

The purpose of the study was to verify in two groups of patients with monocular vision (group 1) and with binocular vision (group 2) to be submitted to cataract surgery in Hospital das Clínicas, São Paulo University Medical School, opinions, expectances and emotional reactions related to the ocular problem, to the quality of vision and to cataract surgery, the influence of monocular or binocular vision in the emotional reactions related to cataract surgery. A transversal comparative and consecutive study was performed using a structured questionnaire applied by interview of patients. The questionnaire was elaborated from a previous exploratory study, the visual acuity and cause of the visual loss were evaluated. The sample was constituted by 96 persons of group 1 (50\% males; $50 \%$ females, ages ranging from 41 to 91 years old; average 69,3 years $\pm 10,4$ years) and 110 persons of group 2 (40,9\% males; $59,1 \%$ females, ages ranging from 40 to 89 years old; average 68,2 years $\pm 10,2$ years). The majority of persons of both groups presented low educational level. There was no statistically significant difference between the groups in relation to gender $(p=0,191)$, age $(p=0,702)$ and educational level $(p=$ 0,245 ). No work activity was mentioned in $95,8 \%$ of the persons of group 1 and $83,6 \%$ of group $2(p=0,005)$ and $30,4 \%$ of group 1 informed the impossibility to work due the visual deficiency. It was observed that the visual acuity of the eye to be operated was less than 0,05 in $40,6 \%$ (group 1) and in 33,6\% (group 2), presented visual acuity ranging from 0,05 to 0,25 . Almost the totality of the persons of both groups informed difficulties to perform activities of daily life and qualified as insufficient their visual acuities; $71,9 \%$ of the patients of group 1 and $71,6 \%$ of group 2 informed to know the reason of low vision; among these, $87,1 \%$ of group 1 and $83,3 \%$ of group 2 mentioned cataract as the reason of low visual acuity. Concerning fear, $40,6 \%$ of patients of group 1 and $22,7 \%$ of group 2 informed about fear of the surgical procedure $(p=0,009)$. The causes of fear more frequently reported were: possibility of loss of vision; worsening of vision; complications during the surgical procedure and to die during the surgery. The more preponderant feelings in both groups were: satisfaction knowing that a cataract can be operated with improvement of vision, relief knowing that will be submitted to surgery, doubt about a good result, nervousness. Changes in the life after surgery were mentioned by 90,6\% (group 1) and by $84,6 \%$ (group 2) of the persons. Housework activities, reading and moving around without help were the mentioned activities expected to be performed after surgery. It was concluded that the patients of both groups were submitted to cataract surgery with visual acuities less than the visual acuity ideally indicated; the patients with monocular vision showed visual acuities significantly less in relation to the patients with binocular vision; the majority of the patients of both groups mentioned difficulties to perform daily activities as a consequence of low vision; patients with monocular vision mentioned doubts in relation to the surgical results as compared with the patients with binocular vision; many patients of both groups did not know the cause of the visual difficulty or explained the visual difficulty by other cause than the cataract; patients of both groups were positively expectant in relation to the visual rehabilitation after the surgery.

Descriptors: Cataract Surgery; Monocular Vision; Binocular Vision; Visual Acuity; Psychology; Public Health 
1. Introdução 


\subsection{CEGUEIRA - DEFINIÇÃO E SITUAÇÃO MUNDIAL}

A cegueira é considerada um importante problema de saúde pública. A definição de cegueira baseia-se na acuidade visual, com correção óptica, do olho de melhor visão. Para a Organização Mundial de Saúde (OMS), uma pessoa é considerada cega quando tem acuidade visual menor do que 0,05 no melhor olho, com a melhor correção óptica, assim como a incapacidade visual (baixa visão) é definida como acuidade menor do que 0,10 no melhor olho, com a melhor correção óptica (Thylefors et al., 1995). Caso esta perda visual ocorra em apenas um dos olhos, a pessoa não é considerada cega, mas com um olho cego.

A OMS, na década de 1950, realizou suas primeiras iniciativas em relação à prevenção da cegueira, as quais se direcionavam à prevenção e erradicação do tracoma. Desse modo, auxílios foram destinados para o estudo da magnitude do problema, no intuito de desenvolver pesquisas em busca de melhores alternativas de tratamento para a doença (Resnikoff e Pararajasegaram, 2001).

Em 1978, com objetivos mais abrangentes, como o tratamento da oncocercose, xeroftalmia e catarata, além do tracoma, foi implantado o 
Programa de Prevenção da Cegueira da OMS (Resnikoff e Pararajasegaram, 2001).

Em 1986 iniciou-se no Brasil (Campinas) e no Peru (Chimbote) o Projeto "Zona Livre de Catarata". Para avaliar a problemática da cegueira por catarata, oftalmologistas se deslocavam até as residências da população-alvo de determinadas regiões. Foram estudados obstáculos que dificultavam o acesso dos indivíduos à cirurgia, sendo apresentadas soluções para resolução desses problemas. O projeto se expandiu com sucesso e sua comprovada utilidade levou à disseminação pela América Latina (Kara José et al., 1990).

A OMS, em parceria com o Banco Mundial, em 1993, desenvolveu a Base de Dados de Cegueira e Deficiência Visual. De acordo com os dados encontrados, baseados na população mundial de 1990, estimou-se a existência de 38 milhões de cegos e 110 milhões de deficientes visuais no mundo. Outra análise de dados, baseada na população mundial de 1996, revelou a estimativa de 45 milhões de cegos e 135 milhões de deficientes visuais no mundo (Resnikoff e Pararajasegaram, 2001). Estima-se que esses números aumentem de 1 a 2 milhões a cada ano e que deverão dobrar até 2020 (West e Sommer, 2001). No entanto, os diferentes critérios de definição de cegueira têm dificultado os estudos sobre sua prevalência (Colenbrander, 2002).

Em 1999 foi criado pela OMS, juntamente com algumas entidades governamentais e organizações não-governamentais, grupos e instituições, o Programa "Vision 2020 - the Right to Sight", com os objetivos principais de 
controle específico de doenças, desenvolvimento de recursos humanos e de infra-estrutura e tecnologia apropriada, no intuito de eliminar a cegueira evitável existente no mundo. Espera-se que 100 milhões de pessoas sejam beneficiadas por tal Programa (Pararajasegaram, 1999; Resnikoff e Pararajasegaram, 2001).

A OMS estimou que no ano de 2002 existissem mais de 161 milhões de deficientes visuais no mundo, dos quais 124 milhões eram portadores de baixa visão e 37 milhões, cegos. No que diz respeito à geografia, mais de 90\% das pessoas deficientes visuais habitavam países em desenvolvimento. Quanto à idade, aproximadamente $82 \%$ das pessoas portadoras de cegueira tinham 50 anos e mais (World Health Organization, 2004).

Cerca de $80 \%$ dos casos de cegueira existentes no mundo podem ser evitados ou curados com emprego da tecnologia atualmente disponível (Alves e Kara José, 1996).

\subsection{CEGUEIRA POR CATARATA NO MUNDO}

Denomina-se catarata qualquer opacificação no cristalino, que disperse a luz, sem necessariamente afetar a visão (Brown e Bron, 1996).

Um relatório, realizado pela OMS, em 1998, estimou haver cerca de 19,3 milhões de cegos por catarata bilateral, o que equivale a $43 \%$ do total de cegos no mundo (Reidy et al., 2002). Aproximadamente $50 \%$ dos idosos 
acima de 75 anos apresentam catarata em estágio precoce e $25 \%$ da mesma faixa etária são portadores de opacidades do cristalino em estágio avançado (Owsley e McGwin Jr, 1999). Alguns estudos apontaram a existência da catarata, em algum grau, em $50 \%$ das pessoas de 60 anos ou mais e na quase totalidade dos indivíduos acima dos 80 anos (Chatterjee et al., 1982; Schwab, 1999).

Acredita-se que a catarata seja conseqüência de alterações bioquímicas relacionadas à idade, embora possa também decorrer de problemas durante a gravidez, infecções oculares, alterações metabólicas, traumas, medicações e exposição a radiações. Além disso, pode ser hereditária, estar associada à distrofias, síndromes, doenças sistêmicas ou dermatite atópica. Dessa forma, pode ocorrer em qualquer idade (Ellwein e Kupfer, 1995; Brown e Bron, 1996). É, portanto, uma doença tratável, de etiologia multifatorial, de que pouco se conhece a respeito da prevenção, adiamento ou reversão do seu desenvolvimento. Não há tratamentos clínicos que tenham comprovação científica de eficácia (Alves e Kara José, 1996; Arieta e Kara José, 2001). No entanto, a correção cirúrgica específica permite efetiva recuperação da capacidade visual, acompanhada de benefícios econômicos e sociais para o indivíduo, sua família e comunidade (Kara-Júnior e Arieta, 2001).

A catarata, apesar de ser uma doença passível de recuperação por intervenção cirúrgica apropriada, representa, de forma paradoxal, a causa mais comum de cegueira em todo o mundo (Thylefors et al., 1995). A cirurgia atualmente é quase sempre combinada com o implante de lente 
intraocular. É um procedimento considerado bastante seguro e eficaz, que geralmente proporciona a reabilitação do indivíduo. Na maioria dos casos, trata-se de um procedimento ambulatorial, cujos custos são mais baixos que os da cirurgia com internação. Além disso, com os avanços da técnica cirúrgica, a recuperação pós-operatória tem se tornado cada vez mais favorável e acelerada (Fine et al., 2002; Sommer, 1996).

Nos países em desenvolvimento, a prevalência dessa doença é alta e, devido ao número insuficiente de cirurgias e ao aumento do número de idosos, o problema tende a acentuar no futuro. Estima-se que, nestes países, 90\% dos indivíduos com 65 anos ou mais apresentem catarata (Ellwein e Kupfer, 1995).

O crescimento acelerado da população idosa nesses países tem causado problemas de saúde pública, pois há limitada capacidade de planejamento para uma sociedade em rápido envelhecimento, enquanto há problemas ligados à população mais jovem. Tal situação exige a implementação de políticas e programas, no intuito de reduzir o ônus do envelhecimento na economia e na sociedade, além de garantir acesso à saúde e aos serviços sociais para o idoso, promovendo sua participação ativa na vida social e na produção econômica (Alves e Kara José, 1996). Logo, a dificuldade de acesso à assistência oftalmológica, proveniente tanto do sistema de saúde quanto de fatores individuais e ambientais, impede a utilização do recurso cirúrgico em sua plena potencialidade, ocasionando importante problema de saúde pública (Sommer, 1989; Alves e Kara José, 1996; Kara-Júnior et al., 1996; Kara José e Temporini, 1999). 
No continente africano há aproximadamente 500 oftalmologistas, cerca de 1 para cada 1.000 .000 de pessoas, sendo que apenas uma pequena parcela de médicos atua nos serviços públicos de saúde. No entanto, com auxílio de organizações internacionais de prevenção da cegueira, o número de cirurgias de catarata realizado nos últimos anos, em alguns países africanos, tem aumentado, tanto devido aos investimentos em recursos humanos, quanto ao treinamento de oftalmologistas, no aperfeiçoamento da técnica cirúrgica (Foster, 1991; Brian e Taylor, 2001; Yorston e Abiose, 2001).

Observa-se que o ganho obtido pelo paciente com a cirurgia geralmente é proporcional à gravidade da perda visual causada pela catarata. Atualmente, com os avanços tecnológicos e científicos, os oftalmologistas têm sido encorajados a intervir com procedimento cirúrgico cada vez mais cedo, oferecendo ao paciente rápida recuperação com reabilitação visual satisfatória (Wormald, 1999). Obstbaum (2006) mostrou que $95 \%$ dos pacientes operados de catarata reportaram satisfação com os resultados da cirurgia. Entretanto, Pager (2004), a partir de estudo acerca de expectativas e resultados referentes à cirurgia de catarata, revelou discrepância existente entre melhora da função visual no pós-operatório, satisfação e expectativas mencionadas pelos pacientes. Tielsch et al. (1995) também demonstraram que geralmente as expectativas dos pacientes em relação aos resultados cirúrgicos estão além dos resultados alcançados. 


\subsection{CEGUEIRA POR CATARATA NO BRASIL E AÇÕES PREVENTIVAS}

No Brasil e na América Latina, de um modo geral, estima-se que a prevalência da cegueira seja de 0,5 a 0,6\%. Dessa maneira, considerandose que a população brasileira é de 160 milhões de pessoas, há 700.000 pessoas legalmente cegas no país (Kara-José e Arieta, 2001). Devido às diferenças regionais brasileiras, é possível encontrar áreas com prevalência de cegueira estimada em $0,25 \%$, índices que podem ser comparados àqueles de países desenvolvidos e outras áreas com índices de 0,75\% (Kara José e Arieta, 2000; Kara-Júnior e Arieta, 2001).

A catarata é responsável por cerca de 40 a $50 \%$ dos casos de cegueira no Brasil, havendo incidência anual de dois a três casos de deficiência visual por catarata senil para cada mil habitantes, segundo dados da OMS. Para esses parâmetros, haveria necessidade de 340.000 a 500.000 cirurgias de catarata a cada ano, no intuito de atender à demanda nacional e erradicar a deficiência visual por catarata (Kara-Júnior e Arieta, 2001).

Estima-se que em 1993, tenham sido realizadas 53.744 cirurgias de catarata, contabilizadas pelo Sistema Único de Saúde (SUS), número que representava cerca de $80 \%$ de todas as cirurgias de catarata realizadas no país; apenas $3 \%$ da população brasileira tinham acesso à medicina particular e 17\%, a convênios médicos (Alves e Kara José, 1996). 
Levando-se em consideração o envelhecimento populacional, estimase que em 2020 a população com mais de 50 anos, dos países em desenvolvimento, deve triplicar em relação a 1989 e quadruplicar em 2025. Dessa maneira, seriam necessárias cerca de 450.000 cirurgias por ano para controlar, em prazo razoável, a cegueira causada pela catarata (Alves e Kara José, 1996).

Ações para diminuição da cegueira por catarata têm sido realizadas desde 1986 no Brasil. No intuito de identificar a importância da cegueira por catarata na população idosa do Brasil e do Peru, por solicitação e estímulo da Hellen Keller International e do National Eye Institute (NEI), foram iniciados dois estudos em Campinas e Chimbote, respectivamente, realizando-se triagem domiciliar da população acima dos 50 anos de idade, exame oftalmológico na população abrangida pelo projeto e cirurgia de catarata para os casos de cegueira identificados em hospitais de referência. A partir dessa experiência, evidenciou-se a incidência de $2 \%$ de cegueira por catarata na população pesquisada (Delgado e Kara José, 1996).

Diante dos altos custos do modelo de inquérito domiciliar, além da demora para a sua realização, dos altos índices de recusa por parte dos pacientes e da dificuldade de reprodução em outras regiões, o projeto foi aperfeiçoado pelo Núcleo de Prevenção da Cegueira da Unicamp, dando ênfase na divulgação de material educativo, no autoteste da acuidade visual, na instalação de postos de atendimento na área-alvo, mantendo-se as facilidades de acesso para exame e cirurgia dos casos necessitados. Dessa forma, os custos com o projeto tornaram-se viáveis, sendo o modelo 
reproduzido para outras regiões do Brasil e países da América Latina (Delgado e Kara José, 1996).

Assim, a partir 1987 iniciaram-se no estado de São Paulo, sob a coordenação do Prof. Dr. Newton Kara José, os projetos Zona Livre de Catarata, ou, abreviadamente, Projeto Catarata. Esse programa de prevenção da cegueira visa eliminar obstáculos logísticos para que o indivíduo deficiente visual por catarata receba o tratamento necessário, mediante facilitação do acesso ao exame oftalmológico e à cirurgia. Esse projeto é realizado em dias de final de semana, em geral, um sábado e um domingo, em local que privilegia critério geográfico de proximidade das residências. É realizada divulgação prévia intensa do projeto, local e datas para o atendimento da comunidade (Temporini e Kara José, 1999).

No Hospital das Clínicas da Faculdade de Medicina da Universidade de São Paulo (HC-FMUSP), o Projeto Catarata, também coordenado pelo Prof. Dr. Newton Kara José, foi realizado pela primeira vez em 1996 e, diferentemente dos Projetos Zona Livre de Catarata, que objetivavam o atendimento de pacientes oriundos de regiões demarcadas (bairros ou cidades com população-alvo de até 150.000 habitantes), a forma de divulgação extrapolou-se para além da capital e interior do estado de São Paulo. Essa campanha mostrou a enorme demanda de indivíduos com déficit visual por catarata à espera de tratamento, corroborando os dados dos projetos Zona Livre de Catarata (Alves et al., 1997).

Pesquisas resultantes do Projeto Catarata ressaltaram que para um indivíduo se submeter à cirurgia de catarata, além de preencher os pré- 
requisitos clínicos para a indicação cirúrgica, precisa estar ciente do seu problema ocular, ter conhecimento da existência de tratamento, possuir confiança na possibilidade de recuperação visual e ter condições de acesso à assistência especializada (Kara José et al., 1996; Kara-Júnior et al., 1996; Kara-Júnior et al., 2001; Temporini et al., 2002).

Algumas barreiras de acesso à cirurgia de catarata têm sido descritas. Estas abrangem questões psicológicas, educacionais, econômicas e logísticas. Dessa maneira, o fato de o atendimento médico ser gratuito não significa gratuidade plena do tratamento para o paciente. O reconhecimento pela população da existência de recursos hospitalares gratuitos na própria região de residência não constitui fator suficiente para busca da cirurgia de catarata (Kara José et al., 1996; Kara-Júnior et al.,1996).

Kara José e Temporini (1999) apontaram que 88\% dos indivíduos atendidos em Projeto Catarata referiram busca anterior de serviços oftalmológicos diversos e, apesar de serem atendidos no referido projeto, o problema não havia sido solucionado. Os autores inferiram que medo, conformismo ou falta de confiança no resultado cirúrgico possam ter influído nesses resultados. No entanto, acrescentaram que a aceitação cirúrgica por portadores de catarata sugere que os fatores preponderantes para a exclusão anterior foram logísticos ou econômicos.

Estudos acerca dos Projetos Catarata têm mostrado que as pessoas procuram submeter-se à cirurgia de catarata após medidas educativas e de facilidade de acesso terem sido realizadas (Kara José et al., 1990). Esse fato evidencia a influência dos fatores psicológicos, sociais e culturais no 
comportamento humano, referentes à recuperação de doenças e distúrbios visuais. A importância que o indivíduo confere à sua visão e aos cuidados necessários para preservá-la depende, em grande parte, de padrões sociais, econômicos, hábitos e crenças aprendidos culturalmente (Temporini, 1991).

A presença de conhecimentos errôneos sobre as causas da cegueira em portadores de catarata leva a supor possíveis informações incorretas sobre a possibilidade de reabilitação visual. Considerando-se que o comportamento preventivo é resultado do conhecimento em relação à doença, suas causas e conseqüências, torna-se necessária a implantação de ações de educação em saúde, no intuito de transmitir informação aos pacientes, diminuindo o número de portadores de cegueira no mundo. Assim, a informação, com objetivo de conscientizar que a visão diminuída por catarata pode ser recuperada com tratamento cirúrgico, levando a uma melhora na qualidade de vida e favorecendo a retomada de atividades, gera reflexos positivos no ambiente familiar dos indivíduos com cegueira por catarata (Temporini et al., 2002; Kara José et al., 1996).

\subsection{A EVOLUÇÃO DA CIRURGIA DE CATARATA}

A primeira cirurgia de catarata com êxito foi provavelmente realizada na Índia, por Sushruta, em 600 antes de Cristo. A técnica consistia em luxar o cristalino por inteiro para a cavidade vítrea, o que possibilitava melhora da 
visão. As cirurgias apresentavam complicações freqüentes, como hemorragias, inflamações, descolamento de retina e lesão do corpo ciliar; caso evoluíssem com sucesso, aproximadamente $40 \%$ dos pacientes permaneciam com melhora visual persistente (Neri-Vela, 2000).

A primeira cirurgia pela técnica da extração extracapsular do cristalino (EECP) foi realizada pelo médico Jacques Daviel, em 1749, após constatar o perigo, para o olho, da luxação do cristalino para a cavidade vítrea. Devido à dificuldade de aspirar os restos corticais, considerando que naquela época ainda não se dispunha de microscópio cirúrgico, a EECP era mais fácil e segura quando a catarata era madura do que quando o córtex era liquefeito (Jampel, 1999).

Em 1759, Sharpe descreveu a extração intracapsular do cristalino (EICP), que permitia maior segurança na remoção da catarata. Entretanto, era prudente postergar a indicação da cirurgia, com a acuidade visual comprometida o bastante em ambos os olhos, a fim de que problemas associados à afacia não excedessem àqueles causados pela catarata. No começo do século $X X$, era a técnica cirúrgica mais utilizada, ainda que apresentasse complicações como perda vítrea, descolamento de retina, edema macular cistóide crônico, descompensação corneal e grandes erros refratométricos (Jampel, 1999).

A partir do desenvolvimento do microscópio cirúrgico e da lente intraocular (LIO), Harold Ridley, em 1949, reintroduziu a EECP, com menor incisão e remoção apenas do núcleo do cristalino, permanecendo o saco capsular para dar suporte à LIO. Apesar da diminuição da freqüência de 
complicações relacionadas à perda vítrea e ao tamanho da incisão, a dificuldade de visualização para aspirar o material cortical remanescente e a má qualidade das LIOs, inicialmente utilizadas, resultavam em intensa reação inflamatória após a cirurgia. Assim, essa técnica foi abandonada, voltando a ser utilizada na década de 70 , com melhora de instrumentos, microscópios e LIOs. As incisões menores, a manutenção da cápsula posterior do cristalino intacta e o implante da LIO de câmara posterior mostraram bons resultados cirúrgicos. A partir da década de 80 , a cirurgia de catarata com implante de LIO tornou-se um dos procedimentos cirúrgicos mais realizados no mundo, graças aos benefícios conferidos às pessoas operadas (Ohrloff e Zubcov, 1997; Albanis et al., 1998).

Em 1965, Charles Kelman desenvolveu unidade de irrigação e emulsificação que, com pequena incisão, fragmentava e aspirava o núcleo do cristalino. A primeira geração dos aparelhos de facoemulsificação surgiu em 1970. Em meados dos anos 80, com o aperfeiçoamento dos facoemulsificadores e das LIOs, a técnica da facoemulsificação passou a ter importantes vantagens (Padilha, 1982; Kelman 2002). No Brasil, essa técnica foi introduzida por Pedro Moacyr de Aguiar e Afonso Fatorelli, em 1975 (Padilha, 1982), tornando-se técnica popular em meados da década de 90 (Albanis et al., 1998; Leaming, 1999).

Com o aperfeiçoamento dos aparelhos de facoemulsificação, o acesso fácil à nova tecnologia e implantação de cursos teóricos e práticos, muitos cirurgiões passaram a adotar a técnica cirúrgica. Vantagens da cirurgia com pequena incisão foram evidenciadas; a recuperação visual mais 
rápida e a possibilidade de ser minimizado o poder dióptrico das lentes corretoras foram, também, ganhando preferência da população leiga (KaraJúnior e Arieta, 2001).

Os avanços da técnica de facoemulsificação e da EECP com implante de LIO de câmara posterior tendem a propiciar maior segurança e melhores resultados, apresentando baixo índice de complicações cirúrgicas e possibilitando manipulação do poder dióptrico refratométrico do olho com a seleção da LIO, com rápida recuperação pós-cirúrgica. Com o aumento da expectativa de vida e adoção de estilo de vida mais ativo, as pessoas tendem a apresentar sensibilidade às variações na visão de cores, contrastes e acuidade visual que, associada ao conhecimento dos bons resultados cirúrgicos, aumentou a demanda pela cirurgia de catarata (Jampel, 1999).

\subsection{BAIXA VISÃO}

A baixa visão corresponde a um comprometimento importante da função visual. O termo "baixa visão" foi criado em 1953 pelo Dr. Gerald Fonda, sendo substituído pelo termo “visão subnormal”, em 1976. (Veitzman, 2000).

Segundo a OMS, pela determinação de valores de acuidade visual no melhor olho, com a melhor correção óptica, a baixa visão leve está 
compreendida entre $20 / 60(0,33)$ e $20 / 80(0,25)$, a moderada entre $20 / 80$ $(0,25)$ e $20 / 160(0,12)$, a severa entre $20 / 200(0,10)$ e 20/400 $(0,05)$ e a profunda, entre 20/500 $(0,04)$ e 20/1000 $(0,02)$. A cegueira está compreendida na faixa de acuidade visual inferior a 20/400 $(0,05)$ (OMS, 2001).

Baixa visão, ou visão subnormal, descreve uma condição intermediária entre a visão normal e a cegueira e secundária a um acometimento irreversível do sistema visual, na qual o uso da correção óptica para erros refracionais não é suficiente para a melhor resolução visual, com prejuízo na realização de determinadas atividades (Haddad et al., 2001).

Dessa maneira, a OMS define que o portador de baixa visão possui comprometimento funcional da visão, mesmo após tratamento ou correção de erros refracionais comuns e apresenta acuidade visual inferior a 6/18 $(0,33)$ até percepção luminosa e campo visual inferior a 10 graus do seu ponto de fixação, porém utiliza ou é potencialmente capaz de utilizar a visão para planejamento ou execução de tarefas (OMS, 2001).

Deficiência visual é definida como uma situação de diminuição da visão mesmo após tratamento clínico e/ou cirúrgico e uso de lentes convencionais. Compreende a cegueira e a baixa visão. $\mathrm{O}$ indivíduo portador de deficiência visual tem restringida sua orientação, mobilidade e capacidade de realizar tarefas. Pela Classificação Internacional das Deficiências, Incapacidades e Desvantagens (CIDID), elaborada pela OMS, deficiência equivale a toda perda ou anormalidade de uma estrutura ou 
função psicológica, fisiológica ou anatômica; incapacidade é toda restrição ou falta da capacidade de realizar uma atividade na forma ou medida considerada normal para um ser humano, devido a uma deficiência; desvantagem é definida como uma situação desvantajosa para o indivíduo, conseqüente de uma deficiência ou incapacidade, que o limita ou impede o desempenho de funções consideradas normais para sua idade, sexo, fatores culturais ou sociais (Amiralian et al., 2000).

A OMS, em 1997, elaborou uma nova versão da CIDID, enfatizando o apoio, capacidades, contextos ambientais e potencialidades. Assim, em relação à deficiência visual, disfunção corresponde a alterações funcionais, incluindo limitações de acuidade visual, campo visual, sensibilidade aos contrastes e visão de cores causadas por doença ocular; incapacidade é a inabilidade do paciente em efetuar determinada tarefa ou atividade intelectual em decorrência de uma disfunção visual; deficiência, por sua vez, é conseqüência socioeconômica de uma incapacidade visual (Veitzman, 2000).

\subsection{A DEFICIÊNCIA CONGÊNITA}

Uma gravidez geralmente é acompanhada por mudanças na dinâmica familiar desde o momento de sua descoberta. Ao notificarem que o filho nasceu com uma síndrome ou doença que acarrete atraso no desenvolvimento, os pais tendem a enfrentar períodos difíceis (Brito e 
Dessen, 1999). O diagnóstico de cegueira, provavelmente, é um dos maiores choques que os pais podem suportar, em relação às outras condições crônicas (Amiralian, 1997a). Dessa forma, os pais tendem a enfrentar um período de choque como reação inicial, posteriormente, tristeza ou ansiedade e, a seguir, gradualmente, reorganização em direção à aceitação do bebê (Brito e Dessen, 1999).

As anomalias congênitas ocorrem em cerca de 2 a $3 \%$ dos nascimentos vivos. Geralmente as anomalias oculares genéticas estão associadas às más-formações de outras estruturas do organismo e podem afetar a acuidade visual, a visão de cores e contrastes, o campo visual, a estereopsia e a sensibilidade à luz. Muitas doenças que envolvem apenas os olhos são genéticas e muitas síndromes genéticas têm manifestações oculares. Há ainda doenças oculares que têm fator predisponente familiar no mecanismo patogênico, como a degeneração macular senil, estrabismo e erros refracionais. Outras doenças, como o diabetes, que apresentam complicações oftalmológicas importantes, possuem fator hereditário. Dentre as anomalias oculares mais freqüentes que apresentam etiologia genética, estão as más-formações das estruturas do olho (microftalmo, nanoftalmo, anoftalmo, coloboma de papila, macropapila, atrofia óptica de Leber, entre outras), doenças sistêmicas com alterações oculares associadas (mucopolissacaridoses, mucolipidoses, lipidoses, doença de Wilson, síndrome de Marfan, retinoblastoma, entre outras), más-formações oculares de etiologia ambiental (teratógenos, síndrome fetal pelo álcool, rubéola, toxoplasmose, entre outras) (Sallum e Maumenee, 2000). 
A deficiência interfere no desenvolvimento, na aprendizagem, nas relações familiares, na organização dinâmica da personalidade, sendo elemento constitutivo dos aspectos estruturais e funcionais do indivíduo que a possui. A influência da deficiência, entretanto, está relacionada a alguns fatores como o tipo de deficiência, sua intensidade e extensão, época de sua incidência e, principalmente, às oportunidades de desenvolvimento e ajustamento oferecidas ao portador (Amiralian, 1997b). Portanto, ao ser diagnosticada a deficiência visual, é importante que a família esteja orientada sobre a necessidade de oferecer à criança educação rica em estímulos e situações que favoreçam a curiosidade em explorar o ambiente, buscar objetos e descobrir soluções adaptativas (Santos, 2004).

Segundo Botelho et al. (2003), a pessoa que é acometida na infância por uma deficiência visual terá mais chances de reintegrar-se totalmente à vida do que aquele que sofre um corte abrupto das atividades em outra fase do desenvolvimento. Sendo assim, durante a infância a aceitação da deficiência é maior, devido ao convívio precoce com as limitações desencadeadas pela deficiência e sua integração no processo de modificações naturais do desenvolvimento. Por outro lado, segundo Vash (1988), a pessoa que se torna portadora de uma deficiência na primeira ou segunda infância pode, assim como a pessoa que nasce com uma deficiência, estar sujeita ao isolamento, a práticas incomuns de educação (como superproteção ou rejeição) e a separação do usual na vida familiar, no lazer e na educação. 


\subsection{A DEFICIÊNCIA ADQUIRIDA}

A deficiência adquirida ocorre durante alguma época do desenvolvimento. A perda da visão pode acontecer em diferentes idades, por diversas condições e de variadas formas. Pode ocorrer conseqüentemente a uma doença ou acidente. Quando a deficiência acontece na infância, pode haver alterações no processo de aprendizagem do indivíduo; na adolescência, podem ocorrer interferências na busca vocacional; na vida adulta, podem ser afetados os compromissos profissionais, eventualmente interrompendo uma carreira em ascensão e influenciar na relação marital. A velhice é uma fase propensa a variadas doenças, que resultam em incapacitação, limitam a vida relacional e as atividades do cotidiano (Kovács, 1997).

A perda visual instalada durante a adolescência ou idade adulta dificulta o processo de elaboração da nova realidade, pois há uma compreensão total da dimensão da realidade e a tendência é, geralmente, significá-la como o fim de uma vida normal, sem manifestações de enfrentamento dessa realidade. Dessa forma, quando a deficiência é instalada, a pessoa torna-se fragilizada, seus recursos internos são mobilizados, levando-a a atuar no mundo conforme as próprias experiências prévias, recursos de enfrentamento, mecanismos de defesa e percepções. Assim, o funcionamento do indivíduo é influenciado, devendo ser compreendido e respeitado dentro das suas possibilidades e limitações, pois 
a própria personalidade influenciará no problema instalado (Rapport et al., 1981; Botelho et al., 2003).

As reações à aquisição da deficiência dependem de quando e como aconteceu, assim como o tipo da deficiência, gravidade, estabilidade, o sexo da pessoa, recursos interiores, auto-estima, temperamento, apoio familiar, renda, tecnologia disponível, entre outros (Vash, 1988; Leinhaas e Hedstrom, 1994).

O estágio da vida em que se encontra o indivíduo quando adquire uma deficiência influencia os tipos de reações experienciadas. Tal fato ocorre porque a forma como a pessoa é percebida e correspondida pelos outros e as tarefas cotidianas interrompidas, acontecem diferentemente, conforme os estágios de vida. O tipo de instalação da deficiência, a experiência de um encontro muito próximo com a morte, sobrevivendo a episódios de doença ou acidente pode exercer influência na vida do indivíduo nas emoções, valores, crenças e comportamento (Vash, 1988).

Reações emocionais e comportamentais à aquisição da deficiência dependem também das características das pessoas que se tornam deficientes. O sexo, por exemplo, não implica em reações melhores ou piores, mas diferentes. $O$ fato do estilo de vida dependente e passivo para a mulher ser aceito com maior facilidade pela sociedade pode influenciar nessa diferença. Interesses, valores, recursos interiores, flexibilidade, adaptabilidade, maturidade e crenças também são fatores que interferem nas reações às mudanças (Vash, 1988). 
A deficiência adquirida pode ocorrer de maneira súbita ou progressiva. A cegueira adquirida subitamente tende a apresentar inicialmente intensa reação da pessoa ao choque sofrido e, só posteriormente, lamentação pelas perdas e privações que sobrevêm a este. Já na cegueira adquirida progressivamente, a ausência de choque e a possibilidade de convivência com a idéia de que pode vir a tornar-se deficiente visual pode beneficiar os capazes de enfrentar a adversidade, facilitando-lhes o acesso a informações e apoio antes do advento da cegueira; entretanto, por outro lado, pode criar um estado de contínua ansiedade pela ameaça de perigo iminente. Isso evidencia que as características de personalidade das pessoas com cegueira adquirida podem estar mais relacionadas às condições pessoais anteriores à perda do que à ausência de percepção visual (Amiralian, 1997a). Geralmente o indivíduo que sofre uma perda súbita tende a se adaptar à sua nova condição mais vagarosamente do que aquele que teve uma perda gradual (Coday et al., 2002).

Há diferenças significativas entre a pessoa que perde a visão devido a uma moléstia oftálmica qualquer, ao que perde por acidente com ou sem deformidade e ao que perde por câncer. Neste último, por exemplo, não existe só a problemática da cegueira, mas o fato de ser portador de um câncer, com todas as conseqüências de um tratamento oncológico (Cyrillo, 1987).

As deficiências adquiridas estão ligadas à perda ou deterioração de uma parte do organismo podendo ser, por isso, associadas com uma 
vivência de morte em vida. Geralmente ocorrem mudanças corporais, alterações no potencial de realização do indivíduo na vida pessoal e profissional, podendo implicar situações semelhantes ao processo de perda por morte. Diante disso, podem ser percebidas as fases possivelmente vividas por pacientes diante da morte:

- choque: ocorre um estado de anestesia, na tentativa de evitar a dor difícil de suportar;

- negação: o indivíduo age como se o problema não estivesse acontecendo com ele, ou como se nada de grave estivesse ocorrendo. Como todo mecanismo de defesa, esta fase parte de um elemento de proteção importante perante a dor da perda. A sua persistência ou intensificação pode resultar no descuido, na negligência ao tratamento, constituindo-se em perigo à vida;

- raiva: a pessoa passa a perceber a dimensão da perda, sendo importante manifestar raiva pela situação vivida. Geralmente é denominado alguém como culpado pela perda, como o médico que não realizou o diagnóstico em tempo; a enfermeira, que demora para o atendimento; os familiares, que não satisfazem todos os desejos do paciente, ou não podem prometer total recuperação;

- barganha: ocorre uma negociação de troca entre uma promessa de mudança na vida, nos hábitos e, conseqüente fantasia de eliminação do problema; 
- depressão: momento em que a revolta e a raiva cederão lugar ao sentimento de grande perda, muitas vezes resulta numa diminuição de tratamentos e atividades;

- aceitação: é uma possibilidade de convivência com a deficiência, com suas dimensões, limitações e integração na vida. Não deve ser confundida com resignação ou conformação, numa atitude fatalista e sem ação.

Nem sempre tais fases ocorrem em sua totalidade e na ordem citada. Diante dessas, pode-se notar o medo frente ao desconhecido, do processo da doença e do tratamento (Kovács, 1997; Kubler-Ross, 1998). Concordando com essas autoras, Leinhaas e Hedstrom (1994) discutiram o modelo da perda, que é válido para as mais variadas deficiências, ressaltando que a perda visual tende a precipitar um processo de luto ou aflição, semelhante ao da perda de um ente querido. Assim, tal modelo descreve estágios emocionais pelos quais o indivíduo tende a passar, como choque, negação, raiva, barganha, depressão e aceitação. Amiralian (1997a) afirma que a perda da visão é um morrer, é o fim de determinada maneira de viver, significa o término de métodos adquiridos de realizações, a perda de relações humanas estabelecidas e de auto-imagem como vidente.

Segundo Fletcher (1994), as reações emocionais frente à perda visual em adultos geralmente são significativas. Medo é a mais consistente e paralizadora reação, podendo o indivíduo experienciá-la de diversas formas, como medo de tornar-se incapaz em conduzir as próprias atividades e seguir em frente; medo do avanço da perda visual e o medo da impossibilidade de 
poder enfrentar a situação. Essas reações de medo podem ser acompanhadas de depressão, sentimentos de desesperança e ansiedade.

Muitos estudos têm mostrado que, para oftalmologistas, os efeitos secundários à perda visual são menos aparentes que a própria perda, sendo geralmente negligenciados. Depressão, limitações funcionais, prejuízos na qualidade de vida, altos níveis de ansiedade e incapacidade são fatores comumente conseqüentes à perda visual (Gieser, 2004).

Williams et al. (1998) relataram em pesquisa que indivíduos com glaucoma e degeneração macular relacionada à idade (DMRI) manifestaram altos escores de prejuízos na qualidade de vida, bem como ansiedade e depressão, que são compatíveis com escores de pacientes com síndrome de imunodeficiência adquirida e doença pulmonar obstrutiva crônica. Apontaram, ainda, que $79 \%$ dos indivíduos que tinham grave perda visual por DMRI, além de outras comorbidades clínicas, referiram a doença ocular como o pior problema de saúde.

Segundo Barczinski (2001), geralmente são observadas outras perdas aliadas à perda da visão, como a perda da integridade física (o indivíduo sente-se mutilado, diferente do que era anteriormente e diferente das pessoas que o cercam); perda do contato com a realidade; perda das atividades cotidianas (como alimentação e higiene pessoal, que restringem a autonomia); perda da profissão da capacidade de produzir e sentir-se útil; entre outras. 


\subsection{REAÇÕES EMOCIONAIS DE PACIENTES COM INDICAÇÃO CIRÚRGICA}

O adoecimento é sentido pelo paciente como uma ruptura no curso da vida, inadequação, fenômeno indesejado que o acomete e é capaz de modificar toda rotina. Além disso, o adoecimento não acomete unicamente o paciente e sim toda família e o círculo social em que convive. Há diferentes maneiras de reagir à doença e seu tratamento, assim, o significado pessoal e subjetivo que a doença desperta é de fundamental importância, dependendo de características da personalidade, circunstâncias sociais e da própria caracterização da doença e respectivo tratamento (Botega, 2002).

Geralmente o adoecimento é vivido como uma situação inesperada para a qual o indivíduo não está preparado, já que não se escolhe adoecer. Com o procedimento cirúrgico, a situação não é diferente, passa a ser algo novo e desconhecido, o que pode levar a altos níveis de ansiedade e despertar fantasias (Figuera e Viero, 2005; Roth, 2002).

A necessidade de cirurgia, por ser um fator potencialmente estressante, tende a provocar nos pacientes respostas fisiológicas (aumento do pulso, pressão sanguínea), cognitivas (crenças sobre conseqüências negativas e inabilidade de concentração), emocionais (ansiedade e depressão), e comportamentais (Nijkamp et al., 2002). O momento do recebimento da notícia da realização da cirurgia pode, então, ser vivido de diversas maneiras. 
Fighera e Viero (2005), em estudo realizado com pacientes a serem submetidos a cirurgias como histerectomia, varizes e colecistectomia, apontaram que reações emocionais, desencadeadas pelos momentos que antecedem a cirurgia, mobilizam sentimentos ambivalentes em relação ao procedimento, que podem ser percebidas através da díade: medo de que algo aconteça com a cirurgia e necessidade de se submeter à cirurgia em busca de melhora na condição da doença. Essa ambigüidade torna-se responsável por deixar o paciente confuso, pois surge o sentimento de impotência, o desejo de não fazer a cirurgia é vencido pela necessidade de realizá-la.

Ruschel et al. (2000) ressaltaram que um procedimento cirúrgico geralmente tende a ser uma ameaça na vida do indivíduo, pois envolve carga emocional característica e, se os aspectos psicológicos não são levados em consideração na situação de tratamento cirúrgico, poderá haver aumento na predisposição para complicações emocionais, que prejudicam a convalescença acarretando, em algumas situações, complicações no período pós-operatório.

Ressalte-se que emoções (ou afetos) são estados internos caracterizados por cognições, sensações, reações fisiológicas e comportamento expressivo específicos (Davidoff, 1983).

Sentimentos incluem não apenas motivos, como fome e sono, mas também emoções, como alegria e raiva. Os motivos e as emoções estão intimamente relacionados. As emoções podem ativar e dirigir o comportamento da mesma maneira que os motivos o fazem, são 
desencadeadas do exterior, enquanto os motivos são ativados do interior, isto é, as emoções geralmente são despertadas por eventos externos, e as reações emocionais são dirigidas a estes eventos; os motivos são despertados por eventos internos e são naturalmente dirigidos a determinados objetos do ambiente. O motivo geralmente é provocado por uma necessidade específica, enquanto a emoção pode ser provocada por uma ampla variedade de estímulos. Tais definições, portanto, não são absolutas, uma fonte externa pode despertar um motivo, como por exemplo, ocorre quando a visão da comida desperta fome e o desconforto causado por um desequilíbrio homeostático (fome) pode despertar emoções (Atkinson et al., 2002).

O ser humano tende a utilizar recursos que o possibilite projetar e modificar condições nas quais se encontra para adaptar-se melhor às situações adversas. Assim, denomina-se medo quando há percepção de um perigo específico e ansiedade quando o perigo tem um caráter menos definido, é um sinal de alerta, sentido como uma ameaça de perigo iminente. (Haynal e Pasini, 1983).

Davidoff (1983) define ansiedade como uma emoção caracterizada por sentimentos de previsão de perigo, tensão e aflição e pela vigilância do sistema nervoso simpático, e acrescenta que ansiedade e medo podem ser distinguidos entre si por duas dimensões: 1) o objeto do medo é fácil de especificar, ao passo que o da ansiedade, amiúde, não é claro; 2) a intensidade do medo é proporcional à magnitude do perigo, a intensidade da ansiedade tem a probabilidade de ser maior do que o medo objetivo (se for 
conhecido). Entretanto, observa-se que ansiedade e medo não são fáceis de diferenciar, sendo também utilizados indiferentemente por diversos psicólogos.

É natural, portanto, frente ao adoecer, o medo que precede um exame invasivo ou a ansiedade que surge após um comunicado de diagnóstico ou de internação. A presença da ansiedade num paciente em tratamento pode representar uma reação psicológica em relação à doença, ao adoecer e ao ambiente hospitalar. Trata-se de um mal-estar físico e psíquico, com apreensão, palpitação, sudorese e até diarréia intermitente, podendo não se apresentar visível ou claramente manifesta; em alguns casos, só é diagnosticada por informação ou dedução (Cabrera e Sponholz Jr., 2002).

Oliveira e Luz (1992), em estudo com pacientes cardiopatas précirúrgicos, mencionaram que, independentemente do sexo, idade, condição econômica, ou mesmo da cardiopatia, algumas preocupações imediatas e medos estavam presentes na grande maioria dos entrevistados, como medo da morte, da anestesia, de sentir dor, dificuldade em aceitar operar o coração e dificuldade em aceitar internação em Unidade de Terapia Intensiva. Alguns estudos, no entanto, mostraram que mulheres tendem a apresentar maiores níveis de ansiedade no período pré-operatório (Ramsay, 1972; Badner et al., 1990); a falta de experiência cirúrgica prévia está associada com altos índices de ansiedade (Badner et al., 1990); os pacientes que passam por cirurgia eletiva geralmente apresentam-se mais ansiosos (Ramsay, 1972). 
Também a respeito da cirurgia cardíaca, Vargas et al. (2006) apontaram em estudo que pacientes no período logo após a indicação cirúrgica tendem a apresentar medo, preocupação, ansiedade, desconfiança e nervosismo. No entanto, pouco antes da cirurgia, foram observadas esperança na possibilidade de cura e reabilitação, tranqüilidade associada a discursos de crença, fé em Deus e à conversa com pessoas que já haviam passado pelo procedimento, além de alívio em relação à realização da cirurgia que, no caso, era imprescindível para a vida.

Brown (1990), em estudo com pacientes pré-cirúrgicos de cálculo renal, demonstrou que medo em relação à anestesia geral foi o que mais predominou entre os respondentes.

Fighera e Viero (2005) mencionaram que momentos antecedentes à cirurgia são vivenciados pelo paciente de forma dramática e assustadora. $\mathrm{O}$ medo do desconhecido torna-se a principal causa de insegurança e ansiedade do indivíduo, há temor da morte, da anestesia, do procedimento em si e da recuperação. Na tentativa de obter controle sobre a ansiedade e o medo, o paciente tende a buscar algumas estratégias, como depositar confiança na equipe de saúde, religiosidade - acreditar em Deus acima de qualquer coisa, desqualificação dos sentimentos, controle dos pensamentos e ter sempre a companhia de alguém conhecido.

Investigando níveis de ansiedade através do State-Trait Anxiety Inventory (STAI) em pacientes entre os períodos pré e pós-cirúrgico, Johnston (1980) assinalou que resultados com pacientes que seriam submetidos à cirurgia ortopédica ou ginecológica demonstraram altos níveis 
de ansiedade antes da cirurgia, seguidos de redução dos níveis no período pós-operatório.

Estudo com pacientes que aguardavam cirurgia eletiva demonstrou que $55 \%$ dos pacientes expressaram medo diante do procedimento cirúrgico. (Uddin et al., 2002).

Referindo-se ao período pré-operatório de pacientes cardiopatas, Romano (2001) apontou a importância da identificação de como o paciente conduz o seu tratamento, o que influencia tanto no período prévio à cirurgia quanto no pós-operatório. Acrescentou que, ao mesmo tempo em que a paralisação, a falta de movimentação e inquietação, os quais correspondem a alto grau de ansiedade, fazem com que o paciente apresente dificuldades em apreender orientações e informações acerca do tratamento, baixo grau de ansiedade tem relação com ausência de introversões, resultando também em resistência em compreender e reafirmar-se diante da situação. Desse modo, há um nível de ansiedade que deve ser considerado e que impulsiona o sujeito à ação, desde perguntas à equipe, relações com familiares, adesão às próprias restrições e situações que contribuem para o preparo em relação à cirurgia.

Concordando com Romano (2001), Knight e Donnelly (1988) asseguraram que quando o indivíduo apresenta altos níveis de ansiedade, os quais o impedem de falar sobre ou encontrar estratégias de enfrentamento da situação, freqüentemente experienciam dificuldades no período pós-operatório. Esse paciente tende a apresentar-se confuso, com 
raiva, ressentido ou depressivo, sendo mais vulnerável às reações psicóticas.

\subsection{REAÇÕES EMOCIONAIS DE PACIENTES COM INDICAÇÃO CIRÚRGICA DE CATARATA}

A cirurgia ambulatorial apresenta algumas vantagens, tanto para o paciente quanto para seus familiares. Dentre estas, estão diminuição dos riscos de infecção hospitalar, pelo tempo reduzido de permanência do paciente na instituição e por proporcionar-Ihe recuperação mais rápida. Sob o aspecto social, a cirurgia ambulatorial, além de diminuir o desconforto do paciente gerado pelo afastamento do convívio familiar e de amigos, traz a redução de custos para o paciente e para o hospital (Smeltzer e Bare, 1994; Moraes e Peniche, 2003).

Acredita-se, no entanto, que independentemente de ser um procedimento realizado em ambulatório, com algumas vantagens, a cirurgia e a anestesia continuam sendo consideradas responsáveis pelo desencadeamento de reações emocionais dos pacientes, em razão de expectativas, medo, dor ou até mesmo o fato de não ocorrer internação (Moraes e Peniche, 2003).

A partir dos avanços científicos, o aperfeiçoamento contínuo das técnicas cirúrgicas tem tornado a cirurgia de catarata um procedimento 
ambulatorial, com realização de anestesia local e resultados cada vez mais seguros e eficientes (Fine et al., 2002).

Apesar do sucesso conseqüente ao aprimoramento das técnicas cirúrgicas, os pacientes tendem a apresentar altos níveis de medo e ansiedade no período pré-operatório (Foggitt, 2001; Nijkamp et al., 2002; Nijkamp et al., 2004).

Nijkamp et al. (2004) encontraram, a partir da STAI, altos níveis de ansiedade de pacientes no período pré-operatório de catarata, tendo estes níveis decrescido no pós-operatório imediato e aumentado no dia seguinte ao procedimento. Os autores apontaram que a queda da ansiedade no pósoperatório pode estar relacionada com o alívio imediato que o paciente tem logo após o término da cirurgia e que o aumento seguinte provavelmente tem relação com a preocupação e as expectativas do paciente em relação aos resultados cirúrgicos, considerando a nova fase da vida. Tal fato enfatiza a importância da necessidade de aconselhamento médico, também no pósoperatório.

Pesquisa realizada em cinco diferentes momentos: no período em que o paciente aguardava o procedimento cirúrgico, em casa; no hospital, durante o preparo da cirurgia; no dia da cirurgia; nas visitas pós-operatórias; e no período de recuperação (de 1 a 5 meses após a cirurgia) destacou que nos cinco diferentes momentos os pacientes tendem a experienciar medo do prejuízo total da visão, da cirurgia em si, da anestesia, de sentir dor e desconforto, dos possíveis resultados cirúrgicos e complicações. Os autores associaram esses sentimentos à precariedade de instruções oferecidas no 
pré-operatório e à estratégia de enfrentamento individual perante o procedimento. Nesse mesmo estudo, que foi realizado em dois hospitais distintos, nos quais os procedimentos de anestesia diferiram, pois um utilizava a sedação antes da anestesia e o outro não utilizava sedação, observou-se que o medo em relação à anestesia, relatado pelos pacientes do hospital que utilizava a sedação, foi menor quando comparado aos do outro hospital (Nijkamp et al., 2002).

Em resposta à questão aberta abordando fatores que ocasionavam ansiedade e fatores tranqüilizadores no período que antecede a cirurgia de catarata, pacientes apontaram como fatores causadores de ansiedade anestesia local, desconhecimento acerca do procedimento e medo do fracasso do resultado; entretanto, informação, receptividade do oftalmologista e assistência personalizada eram fatores que os deixavam calmos (Nijkamp et al., 2002).

Durante a cirurgia de catarata, os pacientes estão acordados e precisam colaborar com o médico, permanecendo quietos, imóveis e com o olho na mesma posição. Se suas reações emocionais não são consideradas, pode não haver cooperação, com possíveis prejuízos à cirurgia (Morrell, 2001).

Estudo realizado com pacientes a serem operados de catarata pela primeira vez e com pacientes a serem operados pela segunda vez mostrou que escores de ansiedade foram mais altos naqueles que se submeteram pela primeira vez ao procedimento cirúrgico, ao mesmo tempo em que 
salientou que os mais altos índices de ansiedade foram registrados no dia da cirurgia (Mitsonis et al., 2006).

Fagerstrom (1991) revelou em estudo que tanto no período préoperatório, quanto após a cirurgia de catarata, as mulheres tendem a demonstrar mais sintomas somáticos que os homens. Mitsonis et al. (2006) mostraram que os índices de ansiedade e depressão no período préoperatório de catarata também são mais acentuados entre as mulheres.

\subsection{O PACIENTE COM VISÃO MONOCULAR}

Embora pesquisas apontem altas taxas de prevalência da perda de um dos olhos funcionais (Coday et al., 2002; Pomberg e Miller, 2004) , estudos com essa população são raros na literatura (Coday et al., 2002).

Buch et al. (2001) realizaram estudo com 946 indivíduos na Dinamarca, dos quais $4,44 \%$ eram portadores de visão monocular; desses indivíduos, 25\% apresentaram acuidade visual (AV) entre 0,50 e 0,10 no olho contralateral. No Brasil, na literatura pesquisada, foi encontrado apenas um estudo retrospectivo, realizado por Centurion et al. (2000), com 2000 pacientes submetidos à cirurgia de catarata, dos quais 3,05\% apresentavam visão monocular. Verificou-se que $44,20 \%$ dos indivíduos com indicação cirúrgica de catarata e visão monocular apresentavam AV menor que 0,20 e $37,70 \%$, AV entre 0,40 e 0,20. 
Coday et al. (2002) avaliaram o impacto que a condição de visão monocular causou em 65 pacientes, verificaram que o tempo da perda visual era fator importante na adaptação do indivíduo àquela condição, que geralmente é um processo difícil, acompanhado de déficits funcionais, desajustes psicológicos e sociais. Os pacientes reportaram dificuldades em lidar com a aparência física, habilidades no trabalho, prática de esportes, mobilidade, atividades como assistir televisão e realizar leitura.

\subsection{FATORES HUMANOS RELACIONADOS À CIRURGIA DE CATARATA}

De acordo com o Dicionário de Ciências Sociais da Fundação Getúlio Vargas (1986),

opinião é um julgamento, convicção, ponto de vista ou crença, sustentado por uma pessoa sobre determinada questão. Pode ser expressa ou tácita, baseada em julgamentos de valor ou em qualquer espécie de raciocínio ou prova e, para o indivíduo, sua opinião sobre determinada questão pode ser importante, ou não, em graus variados

Expectativa é um estado subjetivo derivado de uma orientação dentro de um processo de tempo, que pode ser descrito em enfoques não-behavioristas como o tipo de experiência que se relaciona ao ajustamento do indivíduo à antecipação de experiências (Dicionário de Ciências Sociais da Fundação Getúlio Vargas, 1986).

Esses fatores fazem parte da esfera subjetiva da personalidade e moldam-se por meio do recebimento dos estímulos do meio psicossocial em que se insere o indivíduo. 
2. Objetivos 
Verificar em dois grupos de pacientes, com visão monocular e com visão binocular, a serem submetidos à cirurgia de catarata no Hospital das Clínicas da Faculdade de Medicina da Universidade de São Paulo (HCFMUSP):

1. opiniões, expectativas e reações emocionais em relação ao problema ocular, à qualidade da visão e à cirurgia de catarata;

2. influência da característica de apresentar visão mono ou binocular nas reações emocionais relacionadas à cirurgia de catarata. 
3. Métodos 


\subsection{TIPO DE ESTUDO}

Foi realizado estudo transversal e comparativo. Foram estudadas opiniões, expectativas e reações emocionais de indivíduos com visão monocular e binocular, a serem submetidos à cirurgia de catarata no HCFMUSP.

\subsection{POPULAÇÃO E AMOSTRA}

A população-alvo foi composta por indivíduos com visão monocular e binocular, a serem submetidos à cirurgia de catarata, de 40 anos e mais, atendidos pela Clínica Oftalmológica do HC-FMUSP. Foram formados dois grupos para efeito de comparação: o grupo 1, constituído por indivíduos com visão monocular, a serem submetidos à cirurgia de catarata no olho funcional e o grupo 2, por indivíduos com visão binocular, a serem submetidos à cirurgia de catarata pela primeira vez, no olho de pior visão. 
A amostra foi composta de forma consecutiva por pacientes que atenderam aos critérios de inclusão do estudo e se dispuseram a ser entrevistados. Constituíram-se os 2 grupos, por amostragem nãoprobabilística.

Considerou-se que o indivíduo apresentava visão monocular se diagnosticada cegueira legal irreversível em um dos olhos - acuidade visual menor ou igual a $0,10(20 / 200)$ pela tabela de Snellen ou campo visual menor do que 20 graus (International Council of Ophthalmology, 2002) e visão binocular se, apesar da opacidade do cristalino, ambos os olhos apresentavam potencial visual, com possibilidade de melhora significativa da acuidade visual após a cirurgia de catarata.

Por se tratar de estudo a considerar algumas variáveis-desfecho, sendo a maioria tipo binomial (sim ou não), comparando dois grupos, para o cálculo do tamanho mínimo da amostra, levou-se em consideração os critérios a seguir:

a) assumir que muitas dessas variáveis têm valor igual a $50 \%$ ( $\pi=$ 0,50), e por ter maior variância, tomá-la como parâmetro principal a ser estimada;

b) tomar a aproximação da distribuição binomial para a distribuição normal;

c) admitir que diferenças de $20 \%$ ou mais entre os parâmetros dos dois grupos implica significado prático;

d) estipular em $5 \%$ o valor máximo para o erro tipo I; 
e) estipular em $20 \%$ o valor do erro tipo II.

Assim, o número mínimo de observações em cada grupo foi de 93.

\subsection{CRITÉRIOS DE INCLUSÃO E EXCLUSÃO}

\section{a) Grupo 1:}

Critérios de inclusão:

- indivíduos de ambos os sexos, com idade igual ou superior a 40 anos, com visão monocular, a serem submetidos à cirurgia de catarata;

- comparecimento à clínica oftalmológica na data e horário marcados para realização do procedimento cirúrgico;

- aceitação da entrevista.

Critérios de exclusão:

- não aceitação pelo paciente do procedimento cirúrgico;

- dificuldade de comunicação ou audição e/ou déficit cognitivo. 


\section{b) Grupo 2:}

Critérios de inclusão:

- indivíduos de ambos os sexos, com idade igual ou superior a 40 anos, com visão binocular, a serem submetidos à cirurgia de catarata pela primeira vez;

- comparecimento à clínica oftalmológica na data e horário marcados para realização do procedimento cirúrgico.

- aceitação da entrevista.

Critérios de exclusão:

- não aceitação pelo paciente do procedimento cirúrgico;

- dificuldade de comunicação ou audição e/ou déficit cognitivo. 


\subsection{VARIÁVEIS}

\subsubsection{Variáveis dependentes}

Constituíram as variáveis dependentes:

- opiniões, expectativas e reações emocionais em relação ao problema ocular, à qualidade da visão e à cirurgia de catarata.

Considerando as múltiplas características das variáveis dependentes, foram elas reunidas e classificadas conforme áreas específicas. Registram-se as questões, apresentadas a seguir, por meio das quais foram evidenciadas as variáveis, mencionando-se o número da respectiva questão (Q.).

- Opinião referente ao tempo decorrido da perda visual do olho cego (Q. 6).

- Opinião referente à causa da perda visual do olho cego (Q. 7).

- Expectativas quanto às possibilidades de mudanças na vida em decorrência da perda visual da visão monocular (Q. 8).

- Opinião quanto à dificuldade para realizar atividades de vida diária (Q. 9).

- Opinião referente às atividades que tem dificuldade (Q. 10).

- Opinião referente à qualidade da visão monocular Q. 11).

- Opinião referente ao conhecimento da causa da perda visual da visão monocular (Q. 12). 
- Opinião referente ao grau de medo em relação à cirurgia (Q. 13).

- Opinião em relação à causa do medo da cirurgia (Q. 14).

- Opinião em relação a outros sentimentos manifestados em relação à cirurgia (Q. 15).

- Expectativas em relação à possibilidade de melhora do estilo de vida após a cirurgia (Q. 16).

- Expectativas quanto à realização de atividades após a cirurgia (Q. 17).

\subsubsection{Variáveis independentes}

Foram selecionadas algumas variáveis sócio-demográficas apresentadas a seguir, no intuito de descrever a amostra. As demais variáveis independentes apresentam também função analítica.

- $\operatorname{Sexo}(Q .1)$;

- Idade (Q. 2);

- Escolaridade (Q. 3);

- Situação de trabalho (Qs. 4, 5);

- AV da visão monocular e do olho cego (Itens 18 e 19).

- Diagnóstico médico da perda visual do olho cego (Item 20).

Procedeu-se à seleção de variáveis para efeito de comparação entre os grupos, considerando-se a adequação e a natureza do grupo. 
Para o grupo 2, foram adaptados a questão 11 e os itens 18 e 19, por conta da natureza do grupo, que permaneceram, respectivamente: opinião referente à qualidade da visão do olho a ser operado; AV do olho a ser operado; AV do olho contralateral.

Foram, ainda, excluídas as questões que não se aplicaram à natureza do grupo 2, a saber: Q. 6, 7, 8; além do item 20.

\subsection{INSTRUMENTO}

Para escolha do instrumento utilizado, levou-se em conta a natureza do estudo e da população, além da viabilidade da coleta de dados. Dessa forma, considerando-se a diversidade das características socioculturais, optou-se por realizar o estudo, por meio de questionário elaborado a partir de pesquisa exploratória, entre pacientes com características semelhantes às da amostra (Piovesan e Temporini (1995); Kara-Júnior et al. (2001); Temporini et al. (2002); Temporini e Kara-José (2004)). Esse procedimento metodológico é descrito a seguir.

\subsubsection{Estudo exploratório}

A pesquisa exploratória foi realizada em várias etapas. Na primeira, aplicaram-se entrevistas abertas, livres, prevendo apenas perguntas de 
cunho amplo, de forma a não induzir respostas dos entrevistados. Evitaramse perguntas que pudessem dirigir respostas que o entrevistador tivesse em mente e estabeleceu-se diálogo descontraído com o entrevistado, propiciando-Ihe liberdade de expressão. A finalidade desse tipo de entrevista foi a obtenção do máximo de informações que o indivíduo pudesse oferecer. Nessa etapa da pesquisa, os depoimentos foram gravados, com conhecimento e aquiescência do informante. As entrevistas trouxeram opiniões acerca da qualidade da visão, reações emocionais e expectativas do indivíduo em relação ao respectivo problema. Foram entrevistados 8 pacientes, apresentando características semelhantes às da amostra, sendo 4 do sexo feminino e 4 do sexo masculino, com idades entre 38 e 86 anos. Utilizou-se um roteiro para as entrevistas, contendo apenas tópicos sobre os quais se pretendia conversar. As entrevistas foram realizadas, evitando-se induzir o respondente a manifestar idéias que não fossem suas, ao mesmo tempo em que se procurou verificar o que fazia parte da realidade do entrevistado, sem seleção prévia de informações. Se, no decorrer das entrevistas, a conversa tomou rumos diferentes, porém pertinentes ao objeto de estudo, sendo algo interessante para a pesquisa, o roteiro planejado foi modificado.

O material coletado foi classificado e organizado de acordo com o objeto e objetivo da pesquisa. Assim, os dados foram ordenados e analisados. 
$\mathrm{Na}$ etapa seguinte, foram feitas perguntas mais específicas para a coleta de novas informações. Nas etapas subseqüentes, o objetivo foi apurar mais os resultados obtidos e rever a classificação dos dados.

Encerrou-se a etapa exploratória aos sinais de saturação do assunto, quando nada de novo foi acrescentado aos elementos obtidos.

Tendo o conhecimento do universo de respostas, os dados foram colocados sob forma de perguntas e respostas, aperfeiçoadas progressivamente a partir de sucessivas aplicações, sendo interrompidas no momento em que as informações começaram a se repetir. Foram realizadas entrevistas individuais, com 10 pacientes, com as mesmas características da amostra. Procedeu-se as devidas correções, levando-se em consideração os aspectos que revelaram necessidade de adaptações lingüísticas, como vocabulário popular, expressões e interpretações da população-alvo e de maior dificuldade de compreensão.

$\mathrm{Na}$ última etapa, abordou-se o aspecto quantitativo da pesquisa exploratória. Para realização do pré-teste, o questionário estruturado foi aplicado a uma amostra de tamanho 110, sendo observadas algumas dificuldades para a sua compreensão. O procedimento de elaboração do questionário foi beneficiado com a participação de um número maior de respondentes ao pré-teste, permitindo ajustar questões quanto à clareza. 


\subsubsection{Questionário definitivo}

O questionário definitivo para o grupo 1 foi composto por 17 questões e 3 itens (Anexo A) e para o grupo 2, por 14 questões e 2 itens (Anexo B), elaboradas a partir dos dados dos estudos prévios e de informações obtidas na pesquisa exploratória. Foram incluídas questões abertas e semiestruturadas. Para construção das questões estruturadas, procurou-se obedecer aos princípios de categorização de variáveis (Hulley e Cummings, 1988) e observar a compreensão das escalas pela amostra em estudo.

Optou-se pelo questionário aplicado por meio de entrevista, uma vez que grande parte dos pacientes apresentou baixa escolaridade no estudo exploratório.

\subsection{COLETA DE DADOS}

A aplicação dos questionários foi realizada no período de março de 2006 a março de 2007, no Centro Cirúrgico Ambulatorial do Hospital das Clínicas da Faculdade de Medicina da Universidade de São Paulo, momento em que os entrevistados aguardavam a cirurgia. A coleta de dados foi realizada no dia do procedimento cirúrgico por alguns motivos relacionados à realidade vivida pela população do estudo: dificuldade financeira e/ou de locomoção para deslocamento até o HC-FMUSP para realização da entrevista e tempo parcial determinado para aplicação das entrevistas. 
Dessa forma, o agendamento prévio da cirurgia tornou viável a coleta dos dados.

Cada paciente recebeu explicação a respeito do estudo, a importância da sua colaboração, sendo assegurados a confidencialidade e o anonimato das informações. Garantiu-se que ausência de participação na pesquisa ou seu conteúdo não significariam prejuízo ao tratamento. Após a concordância, foi assinado o Termo de Consentimento Livre e Esclarecido (Anexos C e D).

\subsection{ANÁLISE ESTATÍSTICA}

Inicialmente todas as variáveis foram analisadas descritivamente. Para as variáveis contínuas, a análise foi feita mediante observação dos valores mínimos e máximos, e do cálculo de médias e desvios-padrão. Para as variáveis classificatórias, calcularam-se freqüências absolutas e relativas.

Para os testes de hipóteses de igualdade de proporções entre os dois grupos, aplicou-se a estatística-teste qui-quadrado ou o Teste exato de Fisher, com um nível de significância de 5\% (Rosner, 1986).

A categorização da $\mathrm{AV}$ foi simplificada para efeito de verificar as associações com as variáveis emocionais, sem prejuízo das respectivas graduações. 


\subsection{PROCESSAMENTO DOS DADOS}

O software utilizado para realização das análises foi o SPSS 10.0 for windows.

\subsection{SUBMISSÃO À COMISSÃO DE ÉTICA}

Este estudo foi aprovado pela Comissão de Ética do HC-FMUSP, sob o Protocolo de Pesquisa n 976/04 (Anexo E). 


\section{Resultados}




\subsection{DESCRIÇÃO DA AMOSTRA}

O grupo 1 foi composto por 96 sujeitos, $50,0 \%$ do sexo feminino e 50,0\%, masculino. A idade variou de 41 a 91 anos, com média de 69,3 anos $\pm 10,4$ anos; $29,2 \%$ tinham entre 60 e 69 anos e $36,4 \%$, entre 70 e 79 anos. Quanto à escolaridade, 22,9\% não estudaram e 61,5\% cursaram o ensino fundamental incompleto. O grupo 2 foi constituído por 110 sujeitos, $59,1 \%$ do sexo feminino e 40,9\%, masculino. A idade variou de 40 a 89 anos, com média de 68,2 anos $\pm 10,2$ anos; $29,1 \%$ tinham entre 60 e 69 anos e $42,7 \%$, entre 70 e 79 anos. No que se refere à escolaridade, 14,5\% não estudaram e $67,3 \%$ cursaram o ensino fundamental incompleto. Não houve diferença estatisticamente significante entre os grupos em relação ao sexo $(p=0,191)$, à idade $(p=0,702)$ e à escolaridade $(p=0,245)$ - Tabela 1 . 
Tabela 1 - Características pessoais de pacientes com visão monocular (grupo 1) e com visão binocular (grupo 2), a serem submetidos à cirurgia de catarata. HC-FMUSP - 2007

\begin{tabular}{|c|c|c|c|c|c|}
\hline \multirow{2}{*}{ Características } & \multicolumn{2}{|c|}{ Grupo 1} & \multicolumn{2}{|c|}{ Grupo 2} & \multirow{2}{*}{$\begin{array}{l}\text { valor } \\
\text { de } p\end{array}$} \\
\hline & $\mathrm{n}$ & $\%$ & $\mathrm{n}$ & $\%$ & \\
\hline
\end{tabular}

$\underline{\text { Sexo }}$

Masculino

Feminino

$\underline{\text { Idade (anos) }}$

$$
\begin{aligned}
& 40 \longmapsto 60 \\
& 60 \longmapsto 70 \\
& 70 \longmapsto 80 \\
& 80 \longmapsto 91 \\
& \bar{x}^{2} \pm D P^{3}
\end{aligned}
$$

\section{Escolaridade}

Não estudou

Ensino fundamental

$$
\text { - incompleto }
$$

Ensino médio

$$
\begin{aligned}
& \text { - incompleto } \\
& \text { - completo }
\end{aligned}
$$

Ensino superior

$$
\text { - incompleto }
$$$$
\text { - completo }
$$

$$
\begin{array}{lr}
48 & 50,0 \\
48 & 50,0 \\
n=39
\end{array}
$$

50,0
50,0

45

40,9

$65 \quad 59,1$

0,191 $\mathrm{n}=25$
17

28

35

16

$69,3 \pm 10,4$ anos
$17,7 \quad 18$

16,4

$29,2 \quad 32$

29,1

47

42,7

13

11,8

0,702

$68,2 \pm 10,2$ anos

22

$22,9 \quad 16$

14,5

59

61,5

74

67,3

2

2,1

8

7,3

$\begin{array}{llll}1 & 1,0 & 2 & 2,8 \\ 6 & 6,2 & 7 & 6,4\end{array}$

${ }^{1}$ Teste qui-quadrado; ${ }^{2}$ média; ${ }^{3}$ desvio padrão 
Em relação à situação ocupacional, 95,8\% do grupo 1 não exerciam atividade remunerada; desses, $51,1 \%$ eram aposentados e 30,4\% não tinham possibilidade de trabalhar por causa da deficiência visual. No grupo 2, $83,6 \%$ não exerciam atividade remunerada; desses, $67,4 \%$ eram aposentados. Houve diferença estatisticamente significante entre os grupos em relação à situação ocupacional $(p=0,005)$ e em relação às razões por não trabalhar $(p=0,001)$ - Tabela 2 .

Tabela 2 - Situação ocupacional de pacientes com visão monocular (grupo 1) e com visão binocular (grupo 2), a serem submetidos à cirurgia de catarata. HC-FMUSP - 2007

\begin{tabular}{|c|c|c|c|c|c|}
\hline \multirow{2}{*}{ Situação ocupacional } & \multicolumn{2}{|c|}{ Grupo 1} & \multicolumn{2}{|c|}{ Grupo 2} & \multirow{2}{*}{$\begin{array}{l}\text { valor } \\
\text { de } p\end{array}$} \\
\hline & $\mathrm{n}$ & $\%$ & $\mathrm{n}$ & $\%$ & \\
\hline & \multicolumn{2}{|c|}{$\mathrm{n}=96$} & \multicolumn{2}{|c|}{$n=110$} & \\
\hline Trabalha com remuneração & 4 & 4,2 & 18 & 16,4 & \\
\hline Não trabalha & 92 & 95,8 & 92 & 83,6 & $0,005^{1}$ \\
\hline Razões: & \multicolumn{2}{|c|}{$\mathrm{n}=92$} & \multicolumn{2}{|c|}{$n=92$} & \\
\hline - aposentou-se pela idade & 47 & 51,1 & 62 & 67,4 & \\
\hline $\begin{array}{l}\text { não tem possibilidade de } \\
\text { trabalhar por causa } \\
\text { da deficiência visual }\end{array}$ & 28 & 30,4 & 4 & 4,3 & \\
\hline - atividades do lar & 9 & 9,8 & 10 & 10,9 & \\
\hline · recebe pensão & 8 & 8,7 & 15 & 16,3 & \\
\hline · não consegue trabalho & - & - & 1 & 1,1 & $0,001^{1}$ \\
\hline
\end{tabular}

${ }^{1}$ Teste qui-quadrado 
No grupo 1, a medida da AV da visão monocular revelou 40,6\% de sujeitos que apresentavam $\mathrm{AV}$ igual ou menor do que 0,$05 ; 11,5 \%$ entre 0,10 e 0,$05 ; 22,9 \%$, entre 0,25 e 0,10 . Em relação ao olho cego, $94,8 \%$ tinham AV menor que 0,05 . No grupo 2, 19,1\% tinham AV do olho a ser operado menor que 0,$05 ; 10,0 \%$, entre 0,10 e 0,05 e $44,5 \%$, entre 0,30 e 0,10. Em relação ao olho contralateral, $3,6 \%$ dos pacientes tinham AV menor que 0,$05 ; 17,3 \%$, entre de 0,25 e 0,$05 ; 20,0 \%$, entre 0,30 e 0,25 e $59,1 \%$, acima de 0,3 . Houve diferença estatisticamente significante entre os dois grupos, tanto em relação ao olho a ser operado $(p=0,002)$, quanto ao contralateral $(p<0,001)$ Tabela 3. 
Tabela 3 - Acuidade visual do olho a ser operado e do olho contralateral. Pacientes com visão monocular (grupo 1) e visão binocular (grupo 2), a serem submetidos à cirurgia de catarata. HCFMUSP -2007

\begin{tabular}{|c|c|c|c|c|c|}
\hline \multirow{2}{*}{ Acuidade visual } & \multicolumn{2}{|c|}{ Grupo 1} & \multicolumn{2}{|c|}{ Grupo 2} & \multirow{2}{*}{$\begin{array}{l}\text { valor } \\
\text { de } p\end{array}$} \\
\hline & $\mathrm{n}$ & $\%$ & $\mathrm{n}$ & $\%$ & \\
\hline & \multicolumn{2}{|c|}{$n=96$} & \multicolumn{2}{|c|}{$n=110$} & \\
\hline \multicolumn{6}{|l|}{ Olho a ser operado ${ }^{1}$} \\
\hline$>0,50$ & - & - & 2 & 1,8 & \\
\hline $0,50 \longmapsto 0,30$ & 8 & 8,3 & 27 & 24,6 & \\
\hline $0,30 \vdash 0,25^{3}$ & 16 & 16,7 & 23 & 20,9 & \\
\hline $0,25 \longmapsto 0,10^{4}$ & 22 & 22,9 & 26 & 23,6 & \\
\hline $0,10 \longmapsto-0,05^{5}$ & 11 & 11,5 & 11 & 10,0 & \\
\hline$<0,05^{6}$ & 39 & 40,6 & 21 & 19,1 & 0,002 \\
\hline \multicolumn{6}{|l|}{ Olho contralateral $^{2}$} \\
\hline$>0,50$ & - & - & 24 & 21,8 & \\
\hline $0,50 \longmapsto 0,30$ & - & - & 41 & 37,3 & \\
\hline $0,30 \longmapsto 0,25^{3}$ & - & - & 22 & 20,0 & \\
\hline $0,25 \longmapsto 0,10^{4}$ & - & - & 18 & 16,4 & \\
\hline $0,10 \longmapsto \mid 0,05^{5}$ & 5 & 5,2 & 1 & 0,9 & \\
\hline$<0,05^{6}$ & 91 & 94,8 & 4 & 3,6 & $<0,001$ \\
\hline
\end{tabular}

${ }^{1}$ No Grupo 1 , refere-se à visão monocular; ${ }^{2}$ No Grupo 1 , refere-se ao olho cego; ${ }^{3}$ Baixa visão leve; ${ }^{4}$ Baixa visão moderada; ${ }^{5}$ Baixa visão severa; ${ }^{6}$ Baixa visão profunda (OMS, 2001); ${ }^{7}$ Teste qui-quadrado. 


\subsection{VARIÁVEIS DEPENDENTES}

\subsubsection{Opiniões, expectativas e reações emocionais}

Os pacientes do grupo $1(n=96)$ referiram o tempo e a causa da perda visual: mais de 20 anos (38,5\%); entre 5 e 20 anos $(26,1 \%)$ e menos de 5 anos (35,4\%). Apontaram como causa da perda visual o glaucoma (21,9\%); trauma $(20,8 \%)$ e doença na retina $(19,8 \%)$. Quanto ao diagnóstico médico ( $n=78$ ), foi confirmado que $43,6 \%$ apresentavam doença na retina; $19,2 \%$, trauma e $18,0 \%$, glaucoma. Do total de pacientes, para $18(18,7 \%)$ não se dispunha de prontuários ou estes se mostravam incompletos (Tabela 4).

As tabelas 4 e 5, a seguir, descrevem apenas opiniões de pacientes com visão monocular (grupo 1). 
Tabela 4 - Opinião referente ao tempo decorrido e à causa da perda visual do olho cego e diagnóstico médico. Pacientes com visão monocular, a serem submetidos à cirurgia de catarata (grupo 1). HC-FMUSP - 2007

\begin{tabular}{|c|c|c|c|c|}
\hline Opinião referente à perda visual & $\mathrm{n}$ & $\%$ & & \\
\hline Tempo decorrido (anos) & \multicolumn{2}{|c|}{$n=96$} & & \\
\hline $0 \longmapsto 5$ & 34 & 35,4 & & \\
\hline $5 \longmapsto 20$ & 25 & 26,1 & & \\
\hline $20 \mathrm{e}+$ & 37 & 38,5 & & \\
\hline \multirow[t]{2}{*}{ Causa referida pelo paciente } & \multicolumn{2}{|c|}{$n=96$} & \multicolumn{2}{|c|}{$\frac{\text { Diagnóstico médico }}{(n=78)}$} \\
\hline & & & $n$ & $\%$ \\
\hline Glaucoma & 21 & 21,9 & 14 & 18,0 \\
\hline Trauma & 20 & 20,8 & 15 & 19,2 \\
\hline Doença na retina & 19 & 19,8 & 34 & 43,6 \\
\hline Catarata & 6 & 6,2 & 4 & 5,1 \\
\hline Problema de nascença & 4 & 4,2 & 1 & 1,3 \\
\hline Doença no nervo óptico & 1 & 1,0 & - & - \\
\hline Outra $^{2}$ & 14 & 14,6 & 10 & 12,8 \\
\hline Não sabe & 11 & 11,5 & - & - \\
\hline
\end{tabular}

18 referem-se a prontuários não localizados ou incompletos; ${ }^{2}$ outras causa mencionadas: toxoplasmose, doença de Behçet, acidente vascular cerebral, meningioma, o vento que passou", "o olho grudou e a visão baixou", "ritimia", "quisto no dente" e "furou o pé com prego" 
Quanto às expectativas referentes às possibilidades de mudanças na qualidade de vida, caso perdessem a visão monocular, $65,6 \%$ dos respondentes do grupo 1 afirmaram que a vida mudaria, pois dependeriam de alguém para a realização das atividades diárias e 34,4\% referiram não saber acerca de possibilidades de mudanças na qualidade de vida, caso perdessem a visão do olho monocular (Tabela 5).

Tabela 5 - Expectativas quanto às possibilidades de mudanças na qualidade de vida, caso perdessem a visão monocular. Pacientes com visão monocular (grupo 1), a serem submetidos à cirurgia de catarata. HC-FMUSP - 2007

$\mathrm{n}=96$

\begin{tabular}{lcc}
\hline Possibilidade de mudanças na vida & $\mathrm{n}$ & $\%$ \\
\hline Não mudaria em nada & - & - \\
$\begin{array}{l}\text { Mudaria, pois dependeria de alguém para } \\
\text { realizar as atividades diárias }\end{array}$ & 62 & 65,6 \\
Não sabe & 33 & 34,4 \\
\hline
\end{tabular}

Em relação à dificuldade para realizar as atividades da vida diária, 99,0\% dos pacientes do grupo 1 referiram ter dificuldades. As dificuldades referidas como respostas afirmativas e múltiplas foram: andar na rua (91,6\%); assistir televisão (89,5\%); realizar pequenos consertos $(87,4 \%)$; realizar serviços de casa $(84,2 \%)$; ler $(100,0 \%)$; costurar $(100,0 \%)$; dirigir $(87,5 \%)$. Por não se aplicarem a todos os casos, as três últimas categorias - 
ler, costurar e dirigir - tiveram diferentes valores de "n" - 74, 48 e 24, respectivamente. No grupo $2,96,4 \%$ dos entrevistados mencionaram dificuldades, referindo as respostas afirmativas e múltiplas: andar na rua (88,7\%); assistir televisão (83,0\%); realizar pequenos consertos $(79,2 \%)$; realizar serviços de casa (77,3\%); ler (92,5\%); costurar (95,4\%); dirigir (80,0\%). Por não se aplicarem a todos os casos, as três últimas categorias ler, costurar e dirigir - tiveram diferentes valores de " $n$ " - 94, 65 e 30, respectivamente. (Tabela 6).

Tabela 6 - Opinião quanto à dificuldade visual para realizar as atividades da vida diária. Pacientes com visão monocular (grupo 1) e com visão binocular (grupo 2), a serem submetidos à cirurgia de catarata. HC-FMUSP - 2007

\begin{tabular}{|c|c|c|c|c|c|}
\hline \multirow{2}{*}{ Opinião } & \multicolumn{2}{|c|}{ Grupo 1} & \multicolumn{2}{|c|}{ Grupo 2} & \multirow{2}{*}{$\begin{array}{l}\text { valor } \\
\text { de } p\end{array}$} \\
\hline & $\mathrm{n}$ & $\%$ & $\mathrm{n}$ & $\%$ & \\
\hline & \multicolumn{2}{|c|}{$n=96$} & \multicolumn{2}{|c|}{$n=110$} & \\
\hline Não tem dificuldade & 1 & 1,0 & 4 & 3,6 & \\
\hline Tem dificuldade & 95 & 99,0 & 106 & 96,4 & $0,375^{3}$ \\
\hline Dificuldade para: $^{1}$ & \multicolumn{2}{|c|}{$\mathrm{n}=95$} & \multicolumn{2}{|c|}{$n=106$} & \\
\hline andar na rua & 87 & 91,6 & 94 & 88,7 & $0,493^{4}$ \\
\hline assistir televisão & 85 & 89,5 & 88 & 83,0 & $0,187^{4}$ \\
\hline realizar pequenos consertos & 83 & 87,4 & 84 & 79,2 & $0,125^{4}$ \\
\hline realizar serviços de casa & 80 & 84,2 & 82 & 77,3 & $0,220^{4}$ \\
\hline ler jornal, revista, livro ${ }^{2}$ & 74 & 100,0 & 87 & 92,5 & $0,459^{4}$ \\
\hline costurar $^{2}$ & 48 & 100,0 & 62 & 95,4 & $0,257^{4}$ \\
\hline dirigir $^{2}$ & 21 & 87,5 & 24 & 80,0 & $0,927^{4}$ \\
\hline
\end{tabular}

${ }^{1}$ Respostas afirmativas e múltiplas; ${ }^{2} n \neq 95$ e $n \neq 106$, por não se aplicar ao caso; ${ }^{3}$ Teste exato de Fisher; ${ }^{4}$ teste qui-quadrado 
A totalidade dos pacientes do grupo 1 referiu a visão monocular fraca e $71,9 \%$ mencionaram saber a causa da "visão fraca". Desses, 66,7\% atribuíram a causa apenas à catarata; $17,4 \%$, à catarata associada à outra doença e 15,9\%, a outro fator. No grupo 2, 99,1\% consideraram "fraca" a visão do olho a ser operado; $71,6 \%$ afirmaram saber a causa da "visão fraca". Desses, 69,2\% atribuíram a causa apenas à catarata; 14,1\%, à catarata associada à outra doença e 16,7\%, a outro fator (Tabela 7).

Tabela 7 - Opinião sobre a qualidade da visão e sobre a causa da perda visual. Pacientes com visão monocular (grupo 1) e com visão binocular (grupo 2), a serem submetidos à cirurgia de catarata. HC-FMUSP - 2007

Opinião

Grupo $1 \quad$ Grupo 2

valor

$\begin{array}{cccc}n & \% & n & \text { de } p \\ n n=96 & & n=110\end{array}$

A visão está fraca $96 \quad 100,00 \quad 109 \quad 99,1$

A visão não está fraca

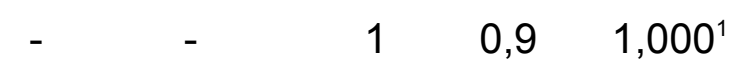

$$
\mathrm{n}=109
$$

$\begin{array}{lllll}\text { Não sabe a causa da visão fraca } 27 & 28,1 & 31 & 28,4\end{array}$

$\begin{array}{llllll}\text { Sabe a causa da visão fraca } & 69 & 71,9 & 78 & 71,6 & 0,960^{2}\end{array}$

$$
\mathrm{n}=69 \quad \mathrm{n}=78
$$

$\begin{array}{lllll}\text { Atribui a causa apenas à catarata } 46 \quad 66,7 & 46 & 69,2\end{array}$

Atribui a causa à catarata associada à outra doença $12 \quad 17,4 \quad 11 \quad 14,1$

Atribui a causa a outro fator

$11 \quad 15,9 \quad 13 \quad 16,7 \quad 0,861^{2}$

\footnotetext{
${ }^{1}$ Teste exato de Fisher; ${ }^{2}$ teste qui-quadrado
} 
Quanto ao medo em relação ao procedimento cirúrgico, 59,4\% dos pacientes do grupo 1 referiram não ter medo; 25,0\%, muito medo e 15,6\%, pouco medo. Dos que revelaram ter medo da cirurgia, preponderaram as respostas acreditar que poderiam perder a visão $(94,9 \%)$, ter a visão piorada $(92,3 \%)$, sofrer alguma complicação na cirurgia $(87,2 \%)$, temer a anestesia $(61,5 \%)$, sentir dor durante o procedimento cirúrgico $(56,4 \%)$, morrer durante a cirurgia $(51,3 \%)$, sentir dor no pós-operatório (51,3\%). No grupo $2,77,3 \%$ revelaram não ter medo do procedimento cirúrgico; $10,0 \%$, ter muito medo e $12,7 \%$, pouco medo. Dos que revelaram ter medo da cirurgia, preponderaram as respostas acreditar que poderiam perder a visão (84,0\%), ter a visão piorada (84,0\%), sofrer alguma complicação na cirurgia $(84,0 \%)$, temer a anestesia $(76,0 \%)$, sentir dor durante o procedimento cirúrgico $(48,0 \%)$, sentir dor no pós-operatório $(48,0 \%)$. Foi observada diferença estatisticamente significante entre os grupos $(p=0,009)$, no que se refere ao grau de medo (Tabela 8). 
Tabela 8 - Opinião referente a grau e causa do medo de pacientes com visão monocular (grupo 1) e com visão binocular (grupo 2), a serem submetidos à cirurgia de catarata. HC-FMUSP - 2007

\begin{tabular}{|c|c|c|c|c|c|}
\hline \multirow{2}{*}{ Opinião } & \multicolumn{2}{|c|}{ Grupo 1} & \multicolumn{2}{|c|}{ Grupo 2} & \multirow{2}{*}{$\begin{array}{l}\text { valor } \\
\text { de } p\end{array}$} \\
\hline & $\mathrm{n}$ & $\%$ & $\mathrm{n}$ & $\%$ & \\
\hline & \multicolumn{2}{|c|}{$n=96$} & \multicolumn{2}{|c|}{$n=110$} & \\
\hline \multicolumn{6}{|l|}{ Grau de medo } \\
\hline Muito medo & 24 & 25,0 & 11 & 10,0 & \\
\hline Pouco medo & 15 & 15,6 & 14 & 12,7 & \\
\hline \multirow[t]{2}{*}{ Não teve medo } & 57 & 59,4 & 85 & 77,3 & $0,009^{2}$ \\
\hline & \multicolumn{2}{|c|}{$n=39$} & \multicolumn{2}{|c|}{$n=25$} & \\
\hline \multicolumn{6}{|l|}{ Causa } \\
\hline achar que pode perder a visão & 37 & 94,9 & 21 & 84,0 & $0,199^{3}$ \\
\hline achar que pode piorar a visão & 36 & 92,3 & 21 & 84,0 & $0,417^{3}$ \\
\hline sofrer complicação na cirurgia & 34 & 87,2 & 21 & 84,0 & $0,728^{3}$ \\
\hline anestesia & 24 & 61,5 & 19 & 76,0 & $0,229^{2}$ \\
\hline sentir dor na cirurgia & 22 & 56,4 & 12 & 48,0 & $0,511^{2}$ \\
\hline sentir dor no pós-operatório & 20 & 51,3 & 12 & 48,0 & $0,798^{2}$ \\
\hline morrer durante a cirurgia & 20 & 51,3 & 3 & 12,0 & $0,001^{2}$ \\
\hline $\begin{array}{l}\text { conhecido realizou a cirurgia e } \\
\text { piorou }\end{array}$ & 5 & 12,8 & 1 & 4,0 & $0,391^{3}$ \\
\hline princípios religiosos & 2 & 5,1 & - & - & $0,516^{3}$ \\
\hline outra & 1 & 2,6 & - & - & $1,000^{3}$ \\
\hline
\end{tabular}

${ }^{1}$ Respostas afirmativas e múltiplas; ${ }^{2}$ teste qui-quadrado; ${ }^{3}$ Teste exato de Fisher 
Dos sentimentos manifestados em relação à cirurgia da catarata, 96,9\% dos sujeitos do grupo 1 mencionaram satisfação por saber que está com catarata, que pode operar e melhorar a visão; 95,8\%, alívio por saber que vai se submeter à cirurgia; $50,0 \%$, dúvida quanto a ter bom resultado cirúrgico; 43,8\%, nervosismo; 40,6\%, inquietação e $36,5 \%$, dúvida quanto à realização da cirurgia. A totalidade dos sujeitos do grupo 2 referiu satisfação por saber que a catarata pode ser operada e melhorar a visão e alívio por saber que vai realizar a cirurgia; $32,7 \%$ revelaram terem ficado nervosos; $30,0 \%$, dúvida quanto a ter bom resultado na cirurgia. Houve diferenças estatisticamente significantes entre os grupos nas categorias alívio por saber que vai se submeter à cirurgia $(p=0,046)$, dúvida quanto a ter bom resultado cirúrgico $(0,003)$, inquietação $(0,001)$, desconforto $(p=0,002)$, sensação de estranheza $(p=0,010)$, confiança em Deus para melhoria da visão $(p=0,001)$, esperança $(p=0,001)$, felicidade $(p=0,024)$ e preocupação ( $p=0,016)$ - Tabela 9 . 
Tabela 9 - Sentimentos manifestados por pacientes com visão monocular (grupo 1) e com visão binocular (grupo 2), a serem submetidos à cirurgia de catarata. HC-FMUSP - 2007 (Respostas afirmativas e múltiplas)

\begin{tabular}{|c|c|c|c|c|c|}
\hline \multirow{2}{*}{ Sentimento } & \multicolumn{2}{|c|}{ Grupo 1} & \multicolumn{2}{|c|}{ Grupo 2} & \multirow{2}{*}{$\begin{array}{l}\text { valor } \\
\text { de } p\end{array}$} \\
\hline & $\mathrm{n}$ & $\%$ & $\mathrm{n}$ & $\%$ & \\
\hline & \multicolumn{2}{|c|}{$n=96$} & \multicolumn{2}{|c|}{$n=110$} & \\
\hline $\begin{array}{l}\text { Satisfação por saber que a } \\
\text { catarata pode ser operada e } \\
\text { melhorar a visão }\end{array}$ & 93 & 96,9 & 110 & 100,0 & $0,100^{1}$ \\
\hline $\begin{array}{l}\text { Alívio por saber que vai ser } \\
\text { operado }\end{array}$ & 92 & 95,8 & 110 & 100,0 & $0,046^{1}$ \\
\hline $\begin{array}{l}\text { Dúvida quanto a ter bom } \\
\text { resultado }\end{array}$ & 48 & 50,0 & 33 & 30,0 & $0,003^{2}$ \\
\hline Nervosismo & 42 & 43,8 & 36 & 32,7 & $0,104^{2}$ \\
\hline Inquietação & 39 & 40,6 & 15 & 13,6 & $0,001^{2}$ \\
\hline $\begin{array}{l}\text { Dúvida quanto à realização da } \\
\text { cirurgia }\end{array}$ & 35 & 36,5 & 30 & 27,3 & $0,157^{2}$ \\
\hline Desconforto & 31 & 32,3 & 16 & 14,5 & $0,002^{2}$ \\
\hline Sensação de estranheza & 27 & 28,1 & 15 & 13,6 & $0,010^{2}$ \\
\hline $\begin{array}{l}\text { Confiança em Deus para } \\
\text { melhoria da visão }\end{array}$ & 26 & 27,1 & 6 & 5,4 & $0,001^{2}$ \\
\hline Tristeza por precisar operar & 25 & 26,0 & 18 & 16,4 & $0,088^{2}$ \\
\hline Irritabilidade & 23 & 23,9 & 19 & 17,3 & $0,235^{2}$ \\
\hline Aperto no peito & 22 & 22,9 & 15 & 13,6 & $0,083^{2}$ \\
\hline Ansiedade & 21 & 21,9 & 14 & 12,7 & $0,081^{2}$ \\
\hline Esperança & 11 & 11,5 & - & - & $0,001^{2}$ \\
\hline Felicidade & 10 & 10,4 & 3 & 2,7 & $0,024^{2}$ \\
\hline Preocupação & 9 & 9,4 & 2 & 1,8 & $0,016^{2}$ \\
\hline Outros $^{3}$ & 4 & 4,2 & - & - & $0,046^{1}$ \\
\hline Raiva por precisar operar & 3 & 3,1 & 2 & 1,8 & $0,666^{1}$ \\
\hline
\end{tabular}


Em relação à melhora da AV após a cirurgia da catarata, no grupo 1, $90,6 \%$ referiram que a vida iria melhorar muito e no grupo $2,84,6 \%$ emitiram a mesma opinião, a diferença entre os grupos não foi estatisticamente significante $(p=0,386)$ - Tabela 10 .

Tabela 10 - Expectativa quanto à possibilidade de melhora do estilo de vida de pacientes com visão monocular (grupo 1) e com visão binocular (grupo 2), a serem submetidos à cirurgia de catarata. HC-FMUSP - 2007

\begin{tabular}{lccccc}
\hline & \multicolumn{2}{c}{ Grupo 1 } & \multicolumn{2}{c}{ Grupo 2 } & $\begin{array}{l}\text { valor } \\
\text { Opinião }\end{array}$ \\
& $\mathrm{n}$ & $\%$ & $\mathrm{n}$ & $\%$ & de $\mathrm{p}^{1}$ \\
\hline A vida melhorará muito & 87 & 90,6 & 93 & 84,6 & \\
A vida melhorará pouco & 8 & 8,3 & 11 & 10,0 & \\
A vida permanecerá como está & - & - & 3 & 2,7 & \\
Não tem opinião & 1 & 1,1 & 3 & 2,7 & 0,386 \\
\hline
\end{tabular}

${ }^{1}$ Teste exato de Fisher

Quanto às expectativas em relação à realização de atividades após a cirurgia da catarata, por meio de respostas múltiplas, $36,5 \%$ dos sujeitos do grupo 1 afirmaram que pretendiam voltar a realizar serviços em casa; 39,2\%, a ler com mais facilidade; $50,0 \%$, a costurar; $24,0 \%$, poder sair sozinho; $62,5 \%$, voltar a dirigir; $13,5 \%$, retornar ao mercado de trabalho. Por não se aplicarem a todos os casos, as categorias ler, costurar e dirigir tiveram diferentes valores de "n" - 74, 48 e 24, respectivamente. No grupo 2, 46,8\% mencionaram pretensão de voltar a ler com mais facilidade; $55,4 \%$, costurar; $50,0 \%$, dirigir e $31,8 \%$, realizar serviços de casa. Por não se aplicarem a 
todos os casos, as categorias ler, costurar e dirigir tiveram diferentes valores de "n" - 94, 65 e 30, respectivamente. Foram observadas diferenças estatisticamente significantes entre os grupos nas seguintes categorias: realizar serviços gerais ( $p=0,002)$, cuidar dos filhos/netos $(p=0,046)$ e ser independente $(p=0,046)$ - Tabela 11

Tabela 11 - Expectativas quanto à realização de atividades após a cirurgia da catarata. Pacientes com visão monocular (grupo 1) e com visão binocular (grupo 2), a serem submetidos à cirurgia de catarata. HC-FMUSP - 2007 (Respostas múltiplas)

\begin{tabular}{|c|c|c|c|c|c|}
\hline \multirow{2}{*}{ Expectativas } & \multicolumn{2}{|c|}{ Grupo 1} & \multicolumn{2}{|c|}{ Grupo 2} & \multirow{2}{*}{$\begin{array}{l}\text { valor } \\
\text { de } p^{1}\end{array}$} \\
\hline & $\mathrm{n}$ & $\%$ & $\mathrm{n}$ & $\%$ & \\
\hline & \multicolumn{2}{|c|}{$\mathrm{n}=96$} & \multicolumn{2}{|c|}{$n=110$} & \\
\hline Realizar serviços de casa & 35 & 36,5 & 35 & 31,8 & $0,483^{2}$ \\
\hline Ler $^{3}$ & 29 & 39,2 & 44 & 46,8 & $0,323^{2}$ \\
\hline Costurar $^{3}$ & 24 & 50,0 & 36 & 55,4 & $0,571^{2}$ \\
\hline Sair sozinho & 23 & 24,0 & 32 & 29,1 & $0,406^{2}$ \\
\hline Dirigir $^{3}$ & 15 & 62,5 & 15 & 50,0 & $0,358^{2}$ \\
\hline Trabalhar & 13 & 13,5 & 25 & 22,7 & $0,090^{2}$ \\
\hline Escrever & 9 & 9,4 & 8 & 7,3 & $0,584^{2}$ \\
\hline Realizar serviços gerais & 8 & 8,3 & - & - & 0,002 \\
\hline Assistir TV & 6 & 6,3 & 5 & 4,5 & $0,587^{2}$ \\
\hline $\begin{array}{l}\text { Realizar exercícios } \\
\text { físicos/esportes }\end{array}$ & 5 & 5,2 & 4 & 3,6 & $0,736^{1}$ \\
\hline Cuidar dos filhos/netos & 4 & 4,2 & - & - & $0,046^{1}$ \\
\hline Reconhecer pessoas & 4 & 4,2 & 1 & 0,9 & 0,186 \\
\hline Ser independente & 4 & 4,2 & - & - & 0,046 \\
\hline Reconhecer objetos & 1 & 1,0 & - & - & 0,466 \\
\hline Ver o mundo como antes & 1 & 1,0 & - & - & 0,466 \\
\hline Viver & 1 & 1,0 & - & - & 0,466 \\
\hline
\end{tabular}

${ }^{1}$ Teste exato de Fisher; ${ }^{2}$ teste qui-quadrado; ${ }^{3} n \neq 96$ e $n \neq 110$, por não se aplicar ao caso 


\subsection{RESULTADOS ANALÍTICOS}

Na comparação realizada entre indivíduos do grupo 1 versus o grupo 2, referente ao sentimento de dúvida quanto a ter bom resultado na cirurgia de catarata, os resultados mostraram-se significantes ( $p=0,003)$, ou seja, predominaram as respostas negativas de presença de dúvida do grupo 2 (Tabela 12).

Tabela 12 - Sentimento de dúvida quanto a ter bom resultado na cirurgia de pacientes com visão monocular (grupo 1) comparado com pacientes com visão binocular (grupo 2), a serem submetidos à cirurgia de catarata. HC-FMUSP - 2007

\begin{tabular}{lcccccc}
\hline & \multicolumn{3}{c}{ Dúvida quanto a ter bom resultado na cirurgia } \\
\cline { 2 - 7 } Grupo & \multicolumn{2}{c}{ Sim } & \multicolumn{2}{c}{ Não } & \multicolumn{2}{c}{ Total } \\
& $\mathrm{n}$ & $\%$ & $\mathrm{n}$ & $\%$ & $\mathrm{n}$ & $\%$ \\
\hline 1 & 48 & 50,0 & 48 & 50,0 & 96 & 100,0 \\
2 & 33 & 30,0 & 77 & 70,0 & 110 & 100,0 \\
\hline
\end{tabular}

Teste qui-quadrado $p=0,003$ 
5. Discussão 
Em 1994, mais de 33 milhões de pessoas tinham 65 anos ou mais, número 11 vezes maior que em 1900, representando $12,5 \%$ da população mundial (Papalia e Olds, 2000).

Segundo a OMS, a expectativa de vida da população mundial no ano 2000 era de 66 anos e passará a ser de 73 anos em 2025 (World Health Organization, 1998). O envelhecimento da população se deve ao avanço da medicina e estilos de vida mais saudáveis (Papalia e Olds, 2000). No Brasil, a expectativa no ano 2000 era de 67 anos e, em 2025 espera-se que passe a ser de 74 anos (World Health Organization, 1998). A comparação com dados de décadas anteriores revela crescimento expressivo na expectativa de vida do brasileiro e, em conseqüência, no número de pessoas idosas (Zimerman, 2000).

O aumento da expectativa de vida é acompanhado pelo impacto cumulativo de doenças crônicas e incapacitantes, dentre estas a deficiência visual (Amiralian, 1997a).

A catarata é responsável pela cegueira de aproximadamente 19,3 milhões de pessoas, $43 \%$ do total mundial (Reidy et al., 2002). 
Apesar da cirurgia de catarata ser um dos procedimentos cirúrgicos mais realizados no mundo e fatores individuais ligados, principalmente à ansiedade e medo do paciente possam interferir na cirurgia (Foggitt, 2001; Nijkamp et al., 2002; Nijkamp et al., 2004), considera-se que aspectos emocionais relacionados à essa cirurgia em pacientes com visão monocular não tenha sido suficientemente estudados.

Participaram deste estudo 206 pacientes, 96 indivíduos com visão monocular e indicação cirúrgica de catarata no único olho funcional (grupo 1) e 110 indivíduos com visão binocular, com indicação cirúrgica de catarata no olho de pior visão (grupo 2).

Em relação às características pessoais, observou-se que não houve diferença estatisticamente significante entre os grupos quanto ao sexo $(p=$ 0,191). O grupo 1 teve proporção igual entre os sexos e o grupo 2 teve proporção maior de mulheres $(59,1 \%)$ - Tabela 1. Javitt et al. (1993) encontraram maior número de pessoas do sexo feminino à procura por tratamento de catarata, provavelmente esses dados estão relacionados com a crescente feminilização do envelhecimento. O aumento da expectativa de vida da população mundial tem demonstrado que mulheres têm expectativa de vida superior à de homens (Papalia e Olds, 2000). Com base na proporção semelhante de indivíduos do sexo masculino e feminino que compuseram o grupo 1, é possível que mulheres com visão monocular tenham mais dificuldade de acesso ou interesse pelo tratamento.

Quanto à faixa etária, observou-se que proporção significativa dos indivíduos, tanto no grupo $1(82,3 \%)$, quanto no grupo $2(83,6 \%)$ possuía 
mais de 60 anos, não havendo, no entanto, diferença estatisticamente significante entre os grupos (Tabela 1). Estudos realizados previamente encontraram dados semelhantes (Kara-Júnior et al., 1996; Temporni et al., 1997).

O nível de escolaridade foi baixo para ambos os grupos: $84,4 \%$ e $81,8 \%$ dos entrevistados dos grupos 1 e 2 , respectivamente, não estudaram ou tinham o ensino fundamental incompleto (Tabela1). Esses dados são característicos de população carente, atendida pelo serviço público em hospital universitário de país em desenvolvimento, como o Brasil (Temporini et al., 1997). Estudos com populações semelhantes, com catarata e da mesma faixa etária, realizados em países desenvolvidos, como os Estados Unidos revelaram nível de escolaridade mais alto, $29 \%$ dos indivíduos tinham concluído nível superior (Steinberg et al., 1994). No presente estudo, apenas $4,2 \%$ e $2,7 \%$ dos entrevistados dos grupos 1 e 2 , respectivamente, tinham concluído o ensino superior.

Houve diferença estatisticamente significante entre os grupos quanto à situação ocupacional, enquanto apenas $4,2 \%$ dos indivíduos do grupo 1 referiram trabalhar com remuneração, 16,4\%, do grupo 2 exerciam atividade remunerada $(p=0,005)$. Os dados sugerem dificuldade existente entre pessoas com catarata e visão monocular para realização de atividades laborais. No grupo $1,30,4 \%$ dos indivíduos que não exerciam atividade remunerada mencionaram não ter possibilidade de trabalhar por causa da deficiência visual, enquanto que no grupo 2, apenas 4,3\% apontaram essa questão. Mais da metade da amostra, em ambos os grupos, referiu ser 
aposentada pela idade, o que está de acordo com a média de idade dos indivíduos - Tabela 2 (Campino e Cyrillo, 2003).

O diagnóstico precoce da catarata, geralmente acompanhado do tratamento efetivo por meio da correção cirúrgica, atualmente realizada com eficácia e segurança, graças ao progresso tecnológico e ao preparo e habilidade dos cirurgiões, permite que o indivíduo não restrinja sua atividade laborativa e se mantenha integrado ao processo social (West e Sommer, 2001; Marback et al., 2005).

West e Sommer (2001) apontaram que, para maior benefício da sociedade, deve-se assegurar que os esforços no combate à catarata se concentrem, também, na prevenção da "cegueira econômica", isto é, quando a dificuldade visual passa a comprometer o desempenho profissional do indivíduo. Os autores estabeleceram que a "cegueira econômica" ocorre quando a AV é menor que 0,30 . O objetivo é evitar a exclusão do mercado de trabalho enquanto a cirurgia é aguardada, uma vez que se torna mais difícil a reintegração de uma pessoa à sociedade após a perda do emprego e da independência social.

Ressalte-se que $75,0 \%$ dos pacientes do grupo 1 apresentaram AV no único olho funcional menor ou igual a 0,25 , justificando a exclusão desses indivíduos do mercado de trabalho (Tabela 3). Centurion et al. (2000), em estudo com pacientes com visão monocular, verificaram que $44,2 \%$ dos indivíduos com indicação cirúrgica de catarata apresentavam AV menor que 0,20 e 37,7\%, AV entre 0,40 e 0,20. No grupo 2 do presente estudo, observou-se que, apesar de $52,7 \%$ dos entrevistados apresentarem AV 
menor ou igual a 0,25 no olho a ser operado, $79,1 \%$ possuíam AV do olho contralateral maior que 0,25 (Tabela 3).

Sabe-se da existência de barreiras socioeconômicas, psicológicas e culturais em relação à busca de assistência oftalmológica (Kara-Júnior et al., 2001; Kara José et al., 1996; Kara José e Temporini, 1999; Temporini e Kara José, 1999; Temporini et al., 2002). No entanto, para os indivíduos com visão monocular, possivelmente há tendência dos médicos oftalmologistas adiarem a indicação da cirurgia, que geralmente ocorre no momento em que há significativo comprometimento visual. No HC-FMUSP, as cirurgias de indivíduos com visão monocular são encaminhadas para cirurgiões com maior experiência (Kara-Júnior, 2003). A aceitação do procedimento cirúrgico pelo paciente também pode se constituir em empecilho que, por já possuir um olho funcionalmente comprometido, busca adiar a realização da cirurgia.

Centurion et al. (2000) em estudo retrospectivo realizado com pacientes com essas características observaram a ocorrência de duas vezes mais complicações per-operatórias em indivíduos com visão monocular. Ademais, as complicações pós-operatórias também foram maiores nesse grupo de pacientes, sugerindo que o retardo da indicação cirúrgica dos cirurgiões oftalmologistas diante de pacientes com essas características se deve, provavelmente, ao fato de existir conotação de maior responsabilidade do cirurgião nesses casos, além disso, há o fato de tais pacientes se submeterem ao procedimento já em estágio avançado da doença, o que pode ser fator limitante da cirurgia. Trotter e Miller (2002) mostraram também 
que pacientes portadores de visão monocular apresentaram maior número de comorbidades nos períodos pré e pós-cirúrgico de catarata do que os pacientes com visão binocular.

Bergwerk e Miller (2000) apontaram a importância da comunicação pré-operatória com o indivíduo com visão monocular, para que as possibilidades de riscos e benefícios sejam estabelecidas e claras. Esses autores referiram tendência de indicar a cirurgia desses pacientes de forma semelhante à dos indivíduos com visão binocular, pois acreditam na importância de tratá-los em tempo hábil, não postergando a cirurgia, a ponto de o paciente não tornar-se incapaz de realizar atividades cotidianas.

Torna-se necessária a rediscussão das indicações da cirurgia, reconhecendo e tratando também os casos em estágios iniciais e que já apresentam algum grau de comprometimento da qualidade de vida do indivíduo. Sabe-se que até há poucas décadas indicava-se cirurgia de catarata quando a $\mathrm{AV}$ era de, aproximadamente, 0,10, quando a incapacidade visual provavelmente já havia prejudicado muito o indivíduo. Nos últimos anos, devido aos avanços e aos bons resultados obtidos com o tratamento, a cirurgia tem sido indicada a pessoas com AV de 0,50 ou mais, a depender do comprometimento da sua qualidade de vida (Klein et al., 1997; Minassian et al., 2000).

Minassian et al. (2000) apontaram como limite superior da AV, a partir da qual se indicaria a cirurgia de catarata no Reino Unido, o de 0,50 , uma vez que o Sistema de Saúde do país poderia absorver tal demanda. Nos Estados Unidos, Klein et al. (1997) também postularam que a AV de 0,50 era 
um limite adequado para a indicação da cirurgia de catarata, pois abaixo desse índice a pessoa já apresenta algumas restrições, como não estar apta a renovar a carteira de motorista.

No Brasil, a literatura é escassa em relação ao limite da AV para indicação da cirurgia de catarata. Observou-se, nos dados obtidos no grupo 2 desse estudo, coerência com os dados citados previamente, tende-se a indicar a cirurgia aos pacientes com AV em torno de 0,50.

No grupo $1,64,6 \%$ dos pacientes havia perdido a visão do olho considerado cego há mais de 5 anos. Quanto à causa da perda visual, $11,5 \%$ mencionaram não saber o motivo; $88,5 \%$ dos entrevistados tinham explicação para a baixa $\mathrm{AV}$, sendo que 48,9\% referiram doenças específicas, como glaucoma, doença na retina ou catarata. Os indivíduos que referiram não saber a causa da perda visual provavelmente não tiveram interesse ou acesso à informação (Tabela 4).

O diagnóstico médico apontou $43,6 \%$ dos casos como doença retiniana, enquanto $19,2 \%$, trauma e $18,0 \%$, glaucoma. Os resultados mostraram que muitos entrevistados desconheciam que doenças retinianas eram causa da perda visual, sugerindo que haja maiores orientações e informações referentes a essas doenças (Tabela 4).

Não foram localizados ou encontravam-se incompletos 18 prontuários. Sabe-se da importância do prontuário no registro de procedimentos e cuidados prestados ao paciente (Westphalen, 2001). Carvalho (2007), em pesquisa realizada no Pronto-Socorro do HC-FMUSP, 
encontrou algumas falhas nos prontuários dos indivíduos do estudo, como prontuários sem diagnóstico, incompletos, inelegíveis ou sem informação do médico. A autora salientou a importância da correção dessas irregularidades, inferindo que falhas nos prontuários médicos dificultam a defesa do profissional em caso de reclamação pelo paciente, além do prejuízo que podem causar ao paciente, no seguimento do caso atendido, e o ressarcimento pelo hospital dos serviços prestados.

Quando indagados sobre as expectativas das possibilidades de mudanças na qualidade de vida em decorrência da perda visual da visão monocular, $65,6 \%$ dos entrevistados referiram que dependeriam de alguém para realizar atividades cotidianas (Tabela 5). Esses dados sugerem que os indivíduos sabem da importância da visão monocular para eles e que a perda desse olho acarretaria em maior comprometimento na qualidade de vida (QV).

Apesar de não existir conceito único, claro e universalmente aceito do termo QV, sabe-se que há dois aspectos relevantes desse conceito: subjetividade e multidimensionalidade (Seidl e Zannon, 2004). Para a Organização Mundial de Saúde, a definição de QV é a percepção do indivíduo de sua posição na vida, no contexto da cultura e do sistema de valores nos quais ele vive e em relação aos seus objetivos, expectativas, padrões e preocupações. É um conceito amplo, que incorpora, de uma maneira complexa, a saúde física, o estado psicológico, o nível de independência, as relações sociais do indivíduo e as suas relações com aspectos proeminentes do seu ambiente (The WOOQOL Group, 1995). 
Assim, a QV representa indicador nos julgamentos clínicos de doenças específicas, avaliando a repercussão física e psicossocial que as enfermidades, disfunções ou incapacidades podem acarretar, permitindo melhor conhecimento do paciente e de sua adaptação à condição (Seidl e Zannon, 2004).

Por resultar na diminuição da $\mathrm{AV}$, a catarata provoca interferências negativas na QV do indivíduo. Estudos de Fagerstrom (1991), assim como Ribeiro et al. (2004), apontaram correlação entre dificuldade visual e níveis indicativos de depressão nos pacientes com história clínica de catarata.

Obstbaum (2006) salientou que a cirurgia de catarata tem tido resultados positivos, em relação à melhora da $\mathrm{AV}$ e na redução dos prejuízos funcionais, com conseqüente melhora da $\mathrm{QV}$.

Williams et al. (1998), em estudo de QV em pacientes com degeneração macular relacionada à idade verificaram, utilizando a escala Quality of Well-Being Scale, que a doença exercia impacto significativo nos diversos domínios da escala, relacionados às atividades diárias dos pacientes.

A baixa $A V$ é responsável pela dificuldade que os indivíduos apresentam para a realização das atividades básicas de vida diária. Como resultados obtidos neste estudo, observou-se que, inclusive, 96,4\% dos indivíduos com visão binocular (grupo 2) revelaram ter dificuldades para realizar suas atividades cotidianas, sendo esse fator revelado por $99,0 \%$ dos entrevistados do grupo 1. Dessa maneira, infere-se que a baixa $A V$, 
decorrente da catarata, afeta aspectos da QV não só dos indivíduos com visão monocular, mas àqueles com visão binocular (Tabela 6).

Lundström et al. (1994), em pesquisa com 150 pacientes com catarata, referiram que a doença tem evolução e adaptação lentas, havendo grandes variações individuais. Apontaram a importância da identificação do grau de deficiência, para que a cirurgia seja realizada antes que importantes atividades de vida diária tenham sido abandonadas.

Dificuldades cotidianas enfrentadas pelos indivíduos portadores de catarata foram destacadas por estudos prévios. Dentre as atividades prejudicadas mais citadas, estavam assistir televisão, reconhecer pessoas e realização de atividades manuais (Kara-Júnior et al., 1996) e realizar atividades em casa, andar sozinho na rua e assistir televisão (Marback et al., 2007).

Neste estudo, evidenciou-se que as atividades andar na rua, assistir televisão, realizar pequenos consertos, realizar serviços de casa, ler, costurar e dirigir foram apontadas, por ambos os grupos, como difíceis de serem realizadas devido à afecção ocular (Tabela 6).

Os resultados expostos na Tabela 7 demonstraram que os entrevistados de ambos os grupos consideram insuficiente suas AVs e proporções significativas afirmaram saber a causa da baixa visão no olho a ser operado. Contudo, $28,1 \%$ do grupo 1 e $28,4 \%$ do grupo 2 relataram não saber a causa da visão fraca, sugerindo carência de esclarecimentos e/ou informações desses indivíduos. Considerando-se que no HC-FMUSP, no 
momento da indicação da cirurgia, as equipes médica e de enfermagem esclarecem ao paciente e acompanhante o problema ocular e a conduta a ser tomada (Kara-Júnior, 2003), provavelmente os pacientes não entenderam a explicação, talvez devido à baixa escolaridade revelada nos resultados deste estudo. Entre aqueles que afirmaram saber a causa da baixa $\mathrm{AV}$ do olho a ser operado, observou-se que $15,9 \%$ dos entrevistados do grupo 1 e 16,7\%, do grupo 2 não apontaram a catarata como causadora da perda visual, provavelmente esses indivíduos também não compreenderam as informações oferecidas pela equipe de saúde do HCFMUSP no momento da indicação cirúrgica (Tabela 7).

A reação emocional medo mostrou-se bastante evidente entre os entrevistados do estudo exploratório, levando à elaboração de uma pergunta específica que abordasse essa reação emocional.

Maior proporção de indivíduos do grupo 1 (25,0\%) referiu muito medo da cirurgia e $10,0 \%$ do grupo 2 emitiram a mesma resposta; $59,4 \%$ e $77,3 \%$ dos grupos 1 e 2, respectivamente, mencionaram não ter medo, sendo a diferença entre os grupos estatisticamente significante $(p=0,009)$. A condição de ter indicação cirúrgica de catarata, por si só, é citada em diversos estudos como causadora de medo (Temporini et al., 1997; Nijkamp et al., 2002; Oliveira et al., 2005; Marback et al., 2007). Estudo realizado em Campinas (Brasil) e Chimbote (Peru) observou que 30,0\% dos indivíduos com diagnóstico de catarata e indicação cirúrgica recusaram a cirurgia devido ao medo do procedimento (Kara José et al., 1990). 
Quando analisadas as causas do medo, observou-se que entre as sensações de poder perder a visão, poder piorar a visão, sofrer complicação na cirurgia, temer a anestesia, sentir dor na cirurgia, sentir dor no pósoperatório, conhecer alguém que realizou o procedimento e piorou, seguir princípios religiosos, não houve diferença estatisticamente significante entre os dois grupos analisados, sugerindo que mesmo os indivíduos com visão binocular têm medo de perder ou piorar a visão. A diferença entre os grupos referente ao medo morrer durante a cirurgia foi estatisticamente significante, sendo mencionado perigo de morte durante a cirurgia por $51,3 \%$ dos indivíduos do grupo 1, fato que não tem relação com a condição do indivíduo de possuir visão mono ou binocular (Tabela 8). Acredita-se que os pacientes com visão monocular tenham mais medo da cirurgia quando comparados com aqueles com visão binocular, porém talvez não consigam definir precisamente a causa desse medo.

Morrer como causa de medo na cirurgia de catarata, entre pacientes brasileiros, foi referida em estudos anteriores por Temporini et al. (1997), Oliveira et al. (2005) e Marback et al. (2007).

O medo referente à anestesia tem sido relatado por diversos estudos, nos mais variados tipos de cirurgia (Brown, 1990; Oliveira e Luz, 1992; Moraes e Peniche, 2003; Fighera e Viero, 2005). Na cirurgia de catarata, Nijkamp et al. (2002) encontraram dados que indicaram como elementos mais estressores do indivíduo a ser submetido à cirurgia a anestesia, a cirurgia em si e o receio de sentir dor. 
Oliveira et al. (2005), em pesquisa com indivíduos a serem submetidos à cirurgia de catarata, reportaram que $40,8 \%$ dos pacientes revelaram medo de sentir dor no procedimento cirúrgico.

Segundo Fighera e Viero (2005), o medo do desconhecido torna-se a principal causa da insegurança e ansiedade do paciente no momento précirúrgico; no estudo, as autoras verificaram que o medo da morte, da anestesia, do procedimento em si e da recuperação foram os mais preponderantes.

Voon et al. (2005), em estudo sobre experiências visuais durante a cirurgia de facoemulsificação com anestesia tópica, afirmaram que o aconselhamento pré-operatório foi responsável pela redução do medo relatado pelos pacientes e acrescentaram que fatores que têm relação com a experiência do medo são: ser jovem, do sexo feminino e estar se submetendo à cirurgia de catarata pela primeira vez.

Quanto aos sentimentos manifestados pelos entrevistados em relação à cirurgia, no momento em que a catarata foi apontada como causa da baixa visual e a cirurgia indicada, como tentativa de solucionar o problema, observou-se que grande maioria dos entrevistados de ambos os grupos referiu satisfação por saber que a catarata pode ser operada e melhorar a visão e alívio por estar aguardando a cirurgia. Os dados referentes à satisfação dos indivíduos por saber da possibilidade de realização da cirurgia, com provável recuperação visual sugerem altas expectativas destes em relação à melhora da AV (Tabela 9). 
Os indivíduos do grupo 1 mencionaram em maior proporção alguns sentimentos: esperança, felicidade, dúvida quanto a ter bom resultado cirúrgico, inquietação, desconforto, sensação de estranheza, confiança em Deus para melhoria da visão e preocupação, com diferenças estatisticamente significante entre os grupos (Tabela 9).

Observa-se que muitos indivíduos tendem a se apegar à religiosidade, provavelmente na tentativa de obter controle sobre a situação que está vivenciando e os entrevistados do grupo 1, provavelmente pela condição de possuir visão monocular, mostraram-se mais confiantes em Deus, na tentativa de resolução dos seus problemas.

Fighera e Viero (2005), em pesquisa com pacientes pré-cirúrgicos de histerectomia, varizes e colecistectomia mostraram como resultado de estudo pré-operatório que os indivíduos confiaram na religiosidade, no intuito de enfrentar a situação. Em pesquisa em Pronto-Socorro oftalmológico de hospital universitário, Carvalho (2007) verificou que, diante do problema ocular, uma das primeiras atitudes dos pacientes era orar à Deus, identificando a forte religiosidade dos indivíduos.

Os sentimentos de esperança e felicidade foram mencionados por $11,5 \%$ e $10,4 \%$ dos indivíduos do grupo 1 , respectivamente; no que se refere ao grupo 2, não houve referência dos entrevistados em relação à esperança e apenas $2,7 \%$ apontaram felicidade, dados que podem estar relacionados à maior necessidade de reabilitação visual dos indivíduos do grupo 1 em relação aos do grupo 2 (Tabela 9). 
A tabela 10 demonstra que os indivíduos contavam com a cirurgia para melhorar o estilo de vida. Observou-se que quase a totalidade dos entrevistados deste estudo esperava melhorar a vida após a cirurgia de catarata, não havendo diferença estatisticamente significante entre os grupos.

A literatura mostra que há 30 anos a técnica cirúrgica mais utilizada para a catarata era a EECP, da qual se observava muitas complicações, com resultados cirúrgicos ruins, que assustavam os indivíduos, afastando-os da realização do procedimento. Contudo, com o desenvolvimento da técnica de facoemulsificação, as complicações cirúrgicas diminuíram consideravelmente, com conseqüente melhora nos resultados e indicação cirúrgica mais precoce, resultando em maior confiança dos pacientes no procedimento (Jampel, 1999), os quais tendem a considerá-lo vantajoso, com resultados "fáceis" e "garantidos" (Kara-Júnior e Arieta, 2001). O perigo dessas concepções é que as altas expectativas dos resultados e o provável desconhecimento das características da técnica, principalmente de riscos e complicações, podem gerar descontentamento em alguns indivíduos que os resultados não sejam exatamente o esperado, principalmente quando se constata que muitos indivíduos não compreendem o motivo da baixa de visão do olho a ser operado, como observado na Tabela 7.

Com relação às expectativas de melhora no desempenho de atividades rotineiras específicas, notou-se que muitos indivíduos de ambos os grupos possuíam expectativas de desempenhar tarefas cotidianas, como realizar serviços de casa, ler, sair sozinho, costurar, dirigir, escrever, as 
quais requerem boa visão. Observou-se que houve diferença estatisticamente significante entre os grupos nas categorias realizar serviços gerais e ser independente, sendo mais apontadas pelos indivíduos do grupo 1, sugerindo grande dificuldade visual destes para realização de funções básicas do cotidiano (Tabela 11).

Embora a diferença entre os grupos não tenha sido estatisticamente significante, maior proporção de indivíduos do grupo 2 referiu expectativas em voltar a trabalhar (22,7\%). Considerando que essas pessoas provavelmente deixaram de trabalhar por causa da limitação visual, estimase que, de acordo com as conclusões de West e Sommer (2001) de que a "cegueira econômica" dificulta a reinserção do indivíduo ao mercado de trabalho, é possível que os entrevistados do grupo 1, com pior visão e provável afastamento das atividades laborais por mais tempo, não priorizem o retorno à vida profissional.

Na comparação entre os grupos referente ao sentimento de dúvida quanto a ter bom resultado na cirurgia de catarata, observou-se a partir da predominância de respostas negativas de dúvida do grupo 2, que houve diferença estatisticamente significante entre os grupos $(p=0,003)$ - Tabela 12. Esses resultados podem sugerir que os indivíduos do grupo 1, por apresentarem menor confiança no sucesso do procedimento, tenham postergado a procura pela cirurgia. A situação adversa de já ter perdido uma visão e a experiência dessa perda, possivelmente, faz com que os indivíduos do grupo 1 consigam se imaginar perdendo a visão do outro olho, enquanto que os do grupo 2, que não passaram pela mesma experiência, não 
consigam se imaginar nessa situação, sendo mais otimistas quanto aos resultados do procedimento cirúrgico.

Algumas limitações deste estudo relacionaram-se ao fato da pesquisa ter sido realizada com indivíduos que compareceram ao HC-FMUSP e se dispuseram a se submeter à cirurgia indicada, não considerando aqueles que não procuraram ou não aceitaram o tratamento por medo ou qualquer outra razão. Sugere-se que estudos com população que não procurou tratamento sejam realizados, no intuito de identificar percepções desses indivíduos. Ressalte-se, então, que as opiniões, expectativas e reações emocionais encontradas nesta pesquisa referem-se a indivíduos que já aceitaram a realização do procedimento cirúrgico.

Outra limitação pode estar relacionada com o fato de que os dados foram coletados em entrevista realizada no dia em que a cirurgia estava marcada, possibilitando que algumas reações emocionais estivessem mais exacerbadas, por ser o momento mais importante do processo de tratamento, enquanto outras reações poderiam estar minimizadas, por já terem sido assimiladas e aceitas pelos pacientes. 
6. Conclusões 
Nas condições desta pesquisa, realizada com 206 indivíduos, com visão mono ou binocular, no dia da cirurgia de catarata, foram obtidas as seguintes conclusões:

- Os indivíduos de ambos os grupos tiveram acesso à cirurgia de catarata com acuidade visual menor do que a idealmente indicada.

- Os pacientes com visão monocular apresentaram acuidade visual significativamente menor em relação aos com visão binocular.

- A maioria dos indivíduos com visão monocular acessou a cirurgia de catarata no momento em que o comprometimento visual já os excluía das atividades laborais (cegueira econômica), enquanto que a maioria dos indivíduos com visão binocular teve acesso ao tratamento quando a acuidade visual ainda lhes permitia condições de exercer tais atividades.

- A maioria dos entrevistados de ambos os grupos referiu dificuldades para realizar atividades cotidianas como conseqüência da baixa visão.

- Os indivíduos com visão monocular referiram mais dúvida em relação aos resultados cirúrgicos do que os com visão binocular. 
- Indivíduos com visão monocular apresentaram mais medo da cirurgia de catarata quando comparados com aqueles com visão binocular.

- Muitos indivíduos de ambos os grupos desconheciam a causa da dificuldade visual ou a atribuíram a outra causa que não a catarata.

- Indivíduos de ambos os grupos apontaram expectativas positivas em relação à reabilitação após a cirurgia. 
7. Sugestões 
- Os indivíduos com visão monocular e binocular devem ser orientados sobre vantagens e desvantagens da cirurgia de catarata.

- Condições de acesso à cirurgia de catarata de indivíduos com visão monocular devem ser criadas antes que a acuidade visual os exclua das atividades laborais.

- O sistema de saúde brasileiro necessita readequação para permitir o acesso à cirurgia de catarata com o mínimo de perda de qualidade de vida dos indivíduos afetados por essa doença. 
8. Anexos 


\section{Anexo A - Questionário aplicado ao Grupo 1}

\section{QUESTIONÁRIO DE PESQUISA}

CIRURGIA DE CATARATA: OPINIÕES, EXPECTATIVAS E REAÇÕES EMOCIONAIS DE PACIENTES COM VISÃO MONOCULAR - 2006/2007 QUESTIONÁRIO No PESQUISADORA: ROBERTA FERRARI MARBACK

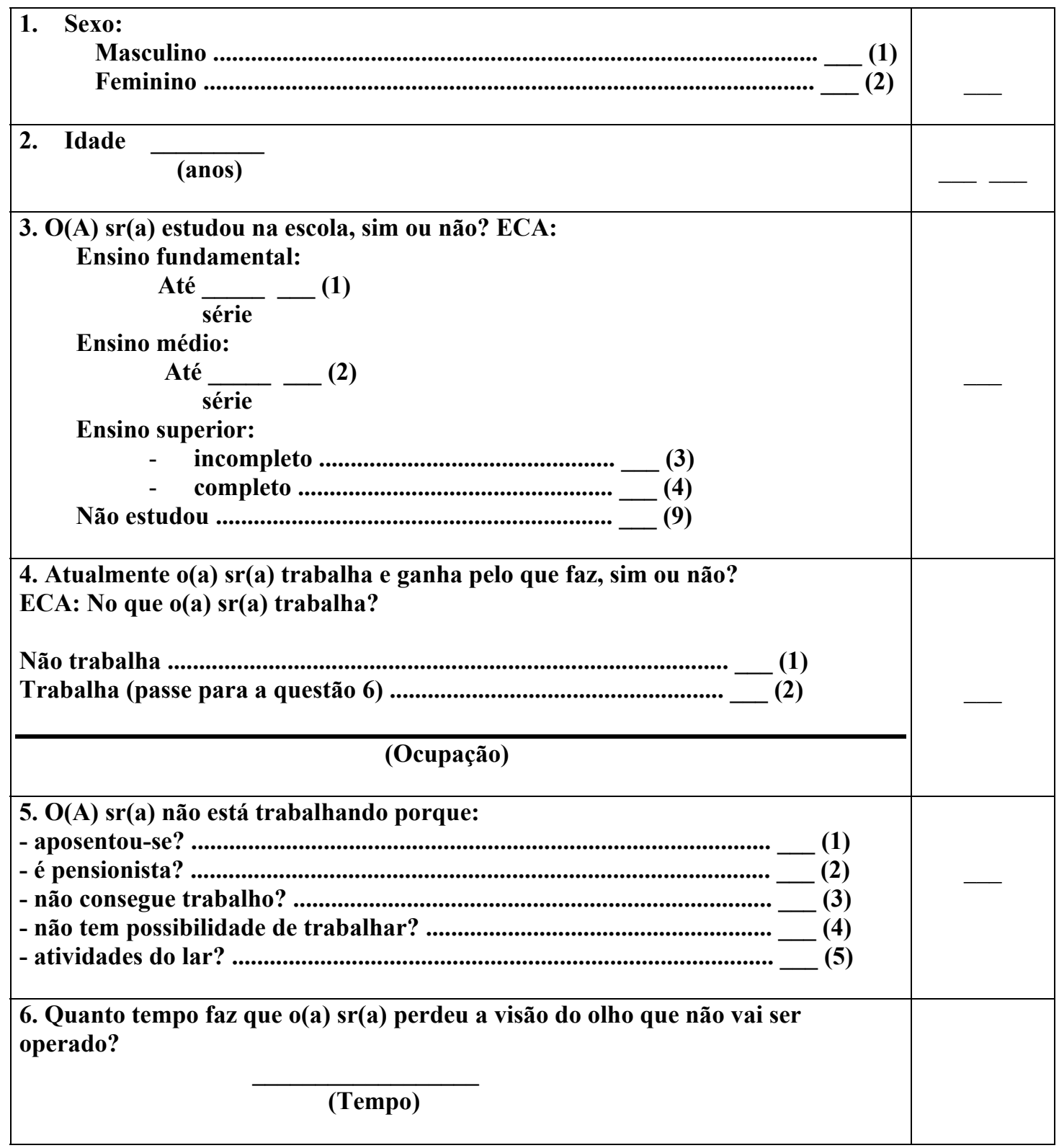




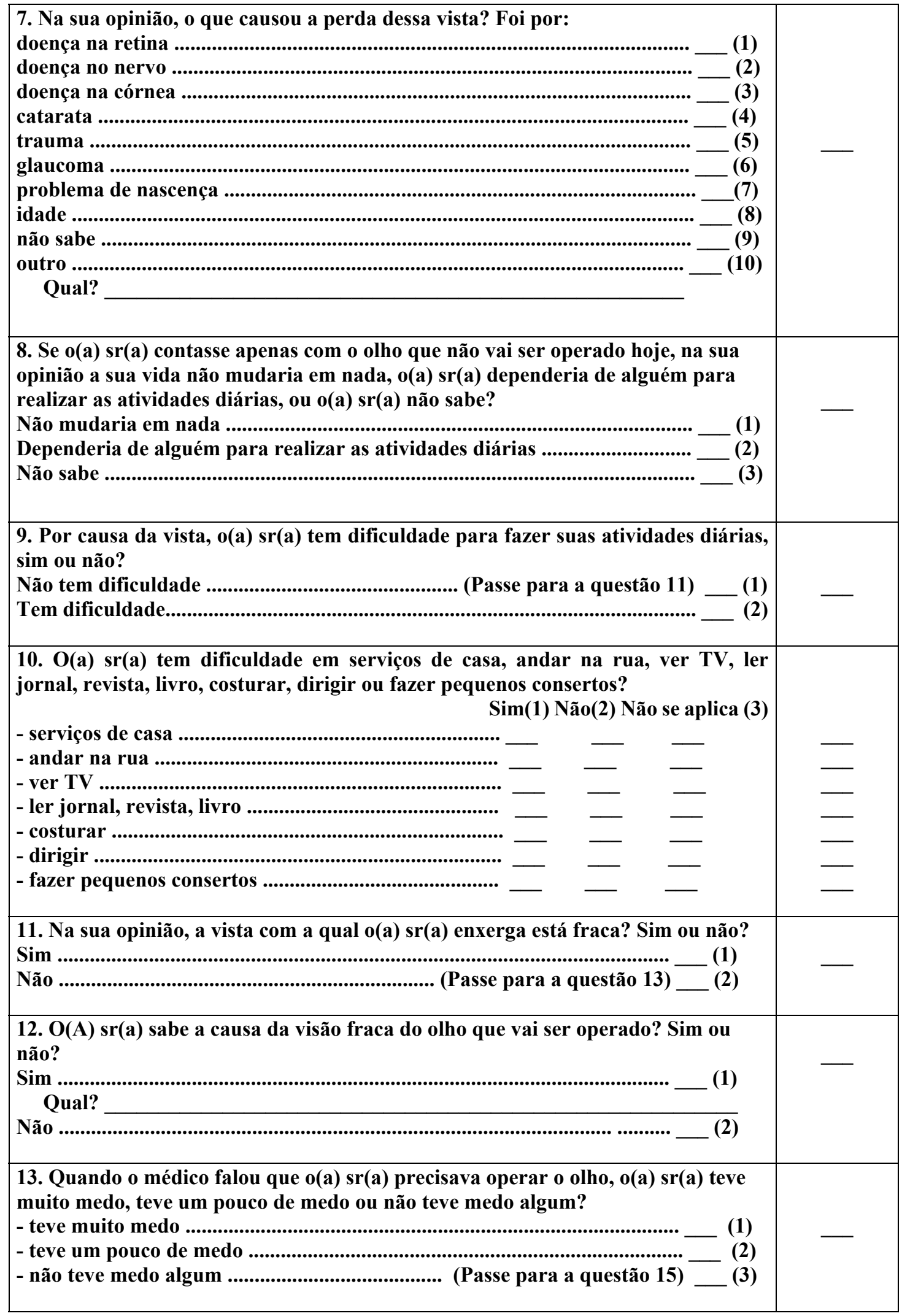




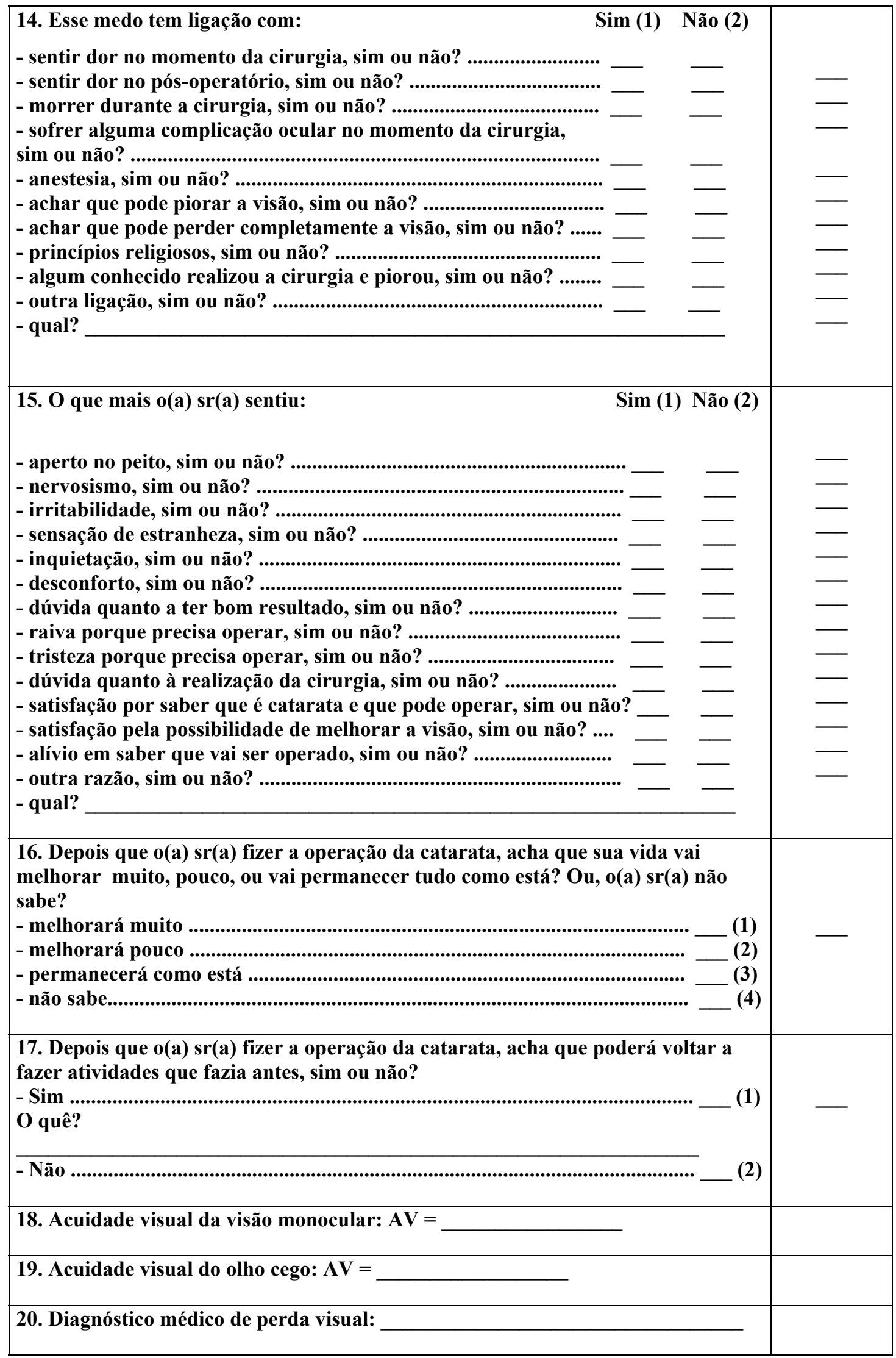




\section{Anexo B - Questionário aplicado ao Grupo 2}

\section{QUESTIONÁRIO DE PESQUISA}

CIRURGIA DE CATARATA: OPINIÕES, EXPECTATIVAS E REAÇÕES EMOCIONAIS DE PACIENTES COM VISÃO BINOCULAR - 2006/2007 QUESTIONÁRIO No

PESQUISADORA: ROBEETT FERRARI MARBACK

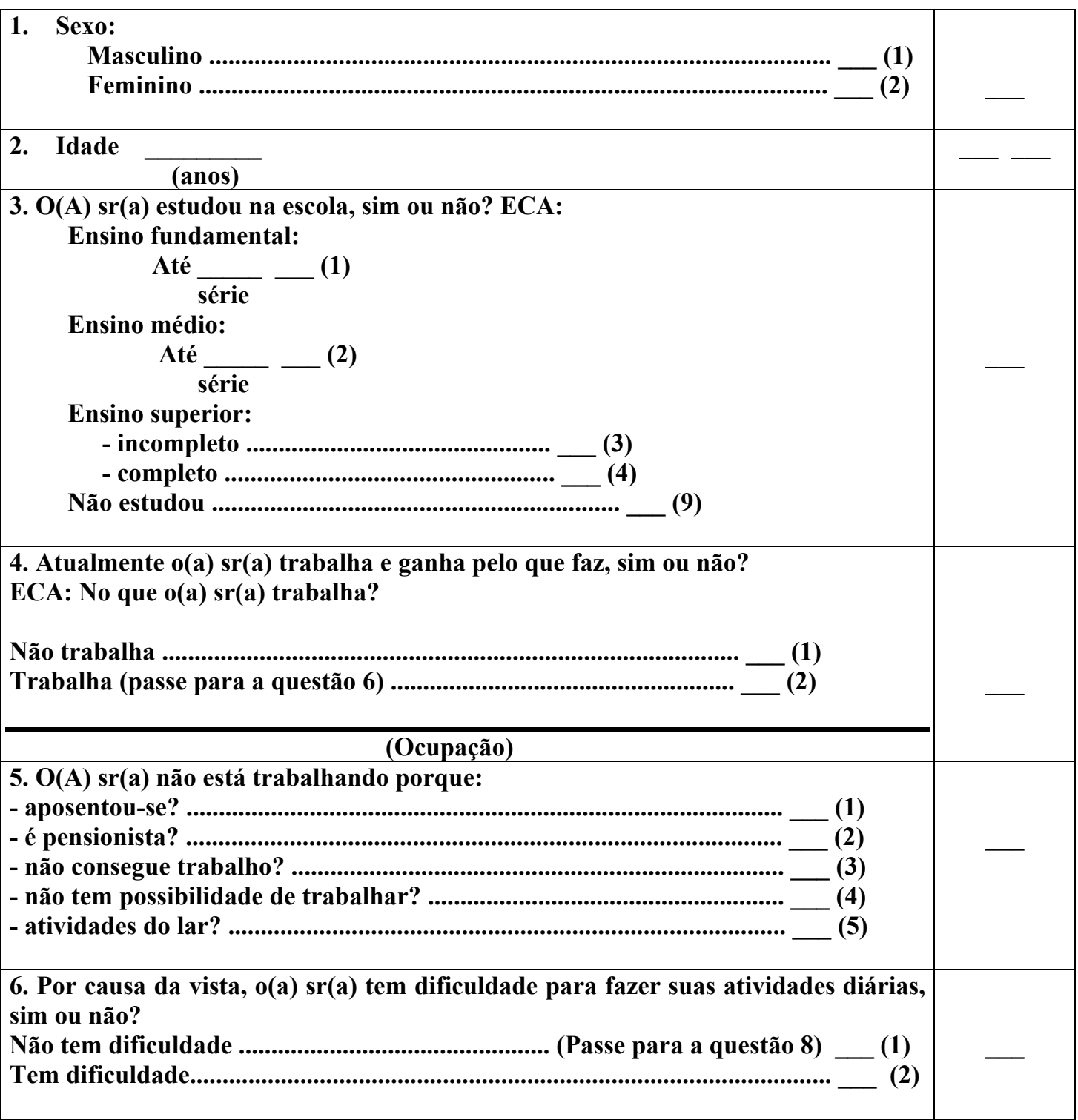




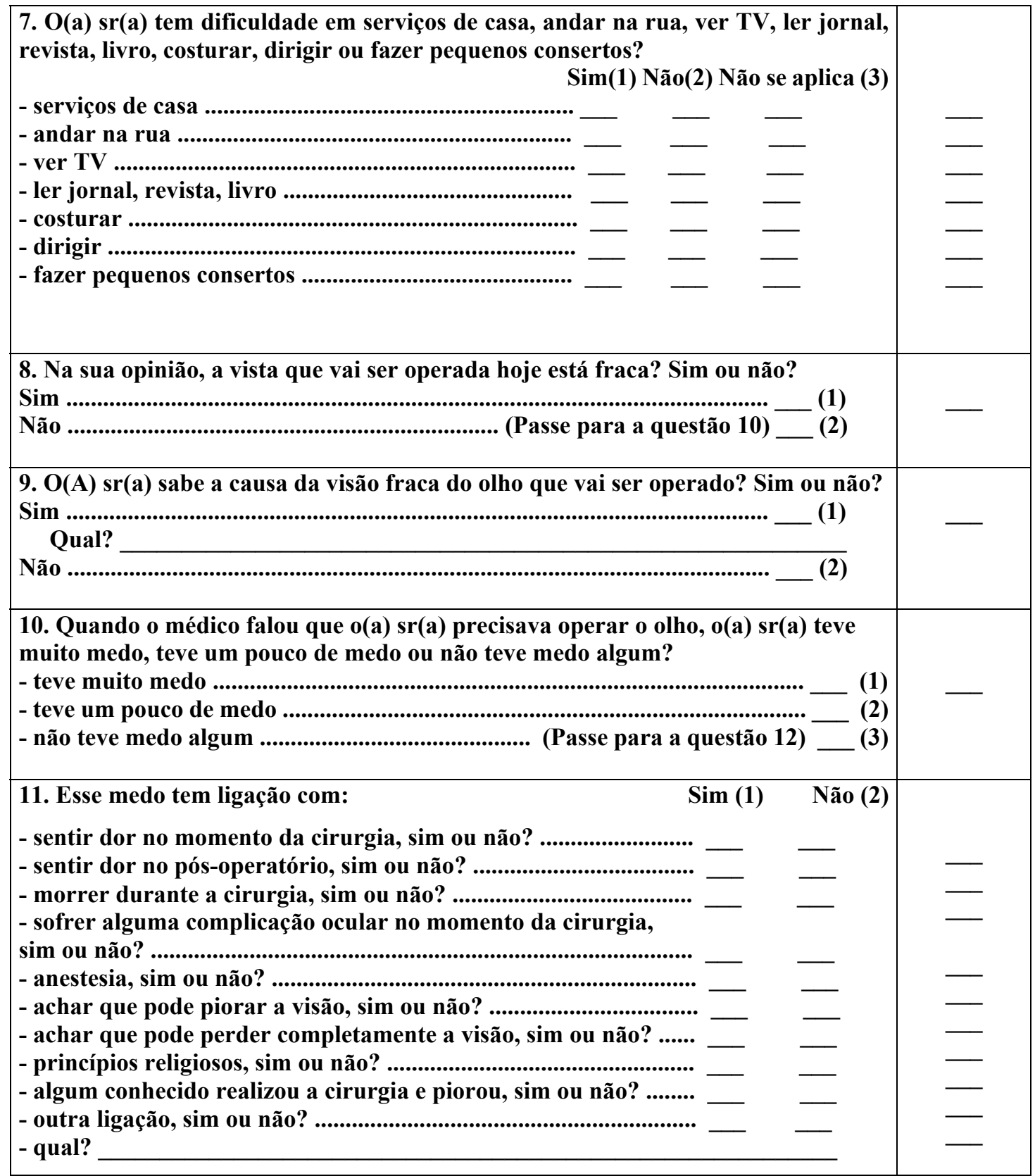




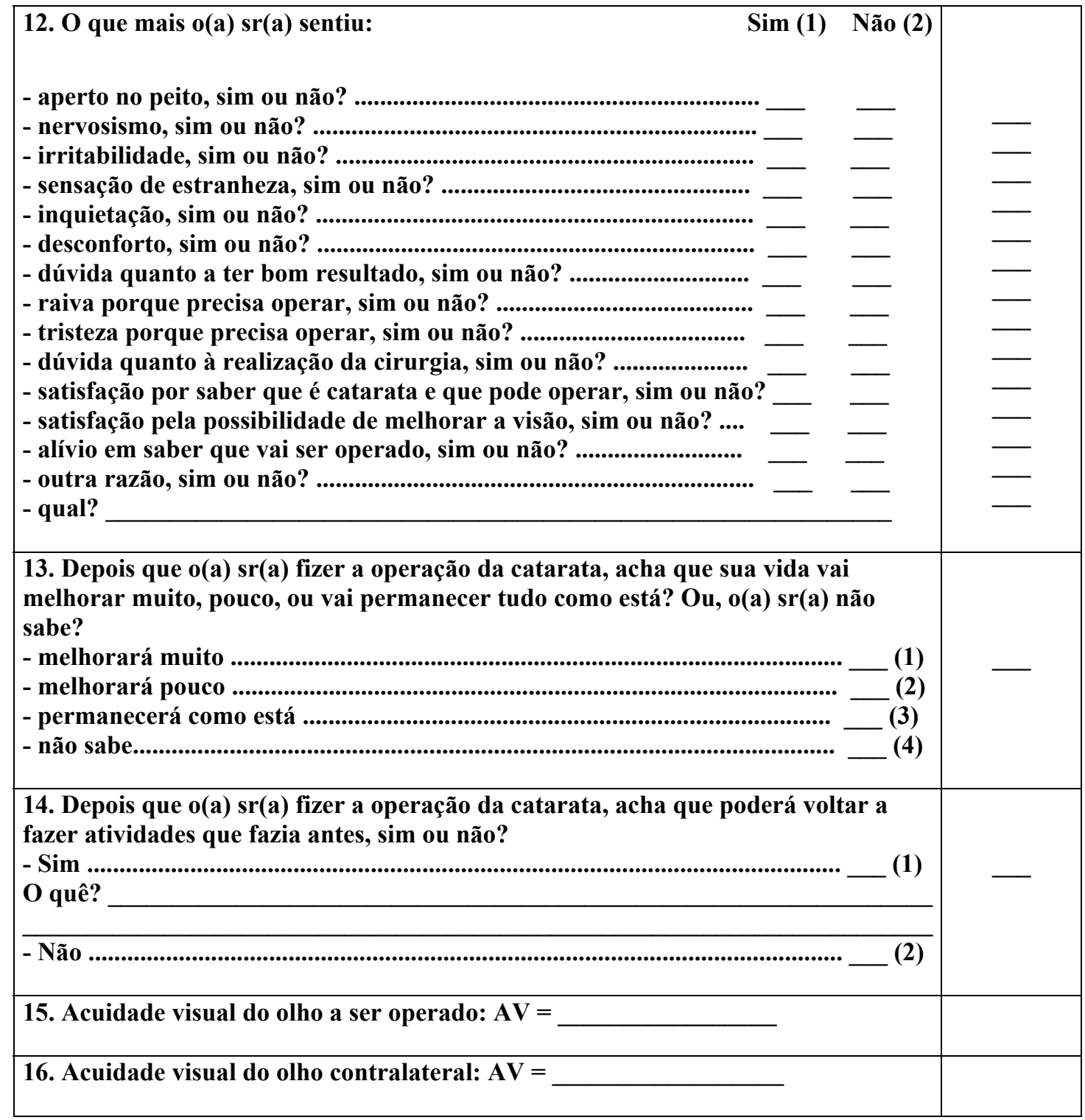




\section{Anexo C - Termo de Consentimento - grupo 1}

Hospital das Clínicas da Faculdade de Medicina da Universidade de São Paulo

\section{Departamento de Oftalmologia}

$\underline{\text { Termo de consentimento livre e esclarecido para o estudo acerca das "Cirurgia }}$ de catarata: opiniões, expectativas e reacões emocionais de pacientes com visão monocular"

Gostaria de saber sua opinião em relação ao estudo que pretendo realizar e dependo das suas respostas. O objetivo do trabalho é buscar saber como você se sente tendo perdido um olho e precisando fazer uma cirurgia de catarata no outro.

A sua colaboração é voluntária, você só participará se quiser. Queria lhe informar que não haverá conseqüência nenhuma no tratamento que você está recebendo aqui, mesmo que você não queira responder, você continuará recebendo o tratamento.

Tudo o que a gente conversar, ficará apenas entre nós, as suas respostas não serão identificadas.

Podemos conversar? Então, por favor, assine aqui:

Eu entendi a descrição do estudo e aceito livremente participar como voluntário da entrevista.

Data: 1

Nome do paciente 


\section{Anexo D - Termo de Consentimento - grupo 2}

Hospital das Clínicas da Faculdade de Medicina da Universidade de São Paulo

\section{Departamento de Oftalmologia}

$\underline{\text { Termo de consentimento livre e esclarecido para o estudo acerca das "Cirurgia }}$ de catarata: opiniões, expectativas e reacões emocionais de pacientes com visão binocular"

Gostaria de saber sua opinião em relação ao estudo que pretendo realizar e dependo das suas respostas. O objetivo do trabalho é buscar saber como você se sente precisando fazer uma cirurgia de catarata.

A sua colaboração é voluntária, você só participará se quiser. Queria lhe informar que não haverá conseqüência nenhuma no tratamento que você está recebendo aqui, mesmo que você não queira responder, você continuará recebendo o tratamento.

Tudo o que a gente conversar, ficará apenas entre nós, as suas respostas não serão identificadas.

Podemos conversar? Então, por favor, assine aqui:

Eu entendi a descrição do estudo e aceito livremente participar como voluntário da entrevista.

Data: 1

Nome do paciente 


\section{Anexo E - Aprovação da Comissão de Ética}

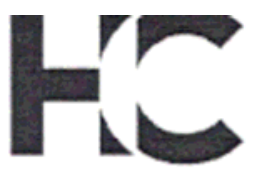

\section{APROVAÇÃO}

A Comissão de Ética para Análise de Projetos de Pesquisa - CAPPesa da Diretoria Clínica do Hospital das Clínicas e da Faculdade de Medicina da Universidade de São Paulo, em sessão de 08.12.04, APROVOU o Protocolo de Pesquisa $n^{\circ}$ 976/04, intitulado: "Percepções sobre perda visual de pacientes de olho único com indicação de cirurgia de catarata" apresentado pelo Departamento de OFTALMOLOGIA E OTORRINOLARINGOLOGIA, inclusive o Termo de Consentimento Livre e Esclarecido.

Cabe ao pesquisador elaborar e apresentar à CAPPesq, os relatórios parciais e final sobre a pesquisa (Resolução do Conselho Nacional de Saúde n 196, de 10.10.1996, inciso IX.2, letra "c").

Pesquisador(a) Responsável: Prof. Dr. Newton Kara José

Pesquisador(a) Executante: Sra. Roberta Ferrari Marback

CAPPesq, 08 de Dezembro de 2004.

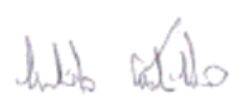

PROF. DR. EUCLIDES AYRES DE CASTILHO

Presidente da Comissão de Ética para Análise de Projetos de Pesquisa 
9. Referências 
Albanis C, Dwyer MA, Ernest T. Outcomes of extra-capsular cataract extraction and phacoemulsification performed in a University training program. Ophthalmic Surg Lasers. 1998;29:643-8.

Alves MR, Kara José N. Catarata: um problema de saúde pública. In: Kara José N, Delgado AMN, Arieta CEL, Rodrigues MLV, Alves MR. Prevenção da cegueira por catarata. Campinas: Editora da Unicamp; 1996. p. 11-8.

Alves MR, Kara José N, Silva ALB, Prado Jr J, Temporini ER. Características e percepções de pacientes portadores de catarata senil atendidos em projeto comunitário de reabilitação visual. Rev Hosp Clin Fac Med S Paulo. 1997;52:16-9.

Amiralian MLTM. Compreendendo o cego: uma visão psicanalítica da cegueira por meio de Desenhos-Estórias. São Paulo: Casa do Psicólogo; 1997a.

Amiralian MLTM. O psicólogo e a pessoa com deficiência. In: Masini EAFS, Becker E, Pinto EB, Amaral LA, Amiralian MLTM, Kovács MJ. Deficiência: Alternativas de Intervenção. São Paulo: Casa do Psicólogo; 1997b. 
Amiralian MLTM, Pinto E, Ghirardi MIG, Lichtig I, Masini EFS, Pasqualin L. Conceituando deficiência. Rev Saúde Pública. 2000;34(1):97-103.

Arieta CEL, Kara José N. Catarata. In: Rodrigues MLV, Dantas AM. Oftalmologia Clínica. Rio de Janeiro: Cultura Médica; 2001. p. 355-72.

Atkinson RL, Atkinson RC, Smith EE, Bem DJ, Nolen-Hoeksema S. Introdução à Psicologia. Porto Alegre: Artmed; 2002.

Badner NH, Nielson WR, Munk S, Kwiatkowska C, Gelb AW. Preoperative anxiety: detection and contributing factors. Can J Anaesth. 1990;37(4):444-7.

Barczinski MCC. Reações psicológicas à perda da visão. Revista do Instituto Benjamim Constant. [periódico online] 2001 [citado Abr 2001 ];18.Disponível em: http://www.ibc.gov.br/?catid=4\&itemid=60.

Bergwerk KL, Miller KM. Outcomes of cataract surgery in monocular patients. J Cataract Refract Surg. 2000;26:1631-7.

Botega NJ. Reação à Doença e à Hospitalização. In: Botega NJ. Prática psiquiátrica no hospital geral: interconsulta e emergência. Porto Alegre: Artmed Editora; 2002. p. 43-59.

Botelho NLP, Volpini M, Moura EM. Aspectos psicológicos em usuários de prótese ocular. Arq Bras Oftalmol. 2003;66(5): 637-46. 
Brian G, Taylor H. Cataract blindness - challenges for the $21^{\text {st }}$ century. Bull World Health Organ. 2001;79(3):249-55.

Brito AMW, Dessen MA. Crianças surdas e suas famílias: um programa geral. Psicologia: Reflexão e Crítica. 1999; 12(2):429-45.

Brown N, Bron AJ. Lens Disorders. Oxford: Butterworth-Heinemann; 1996.

Brown SM. Quantitative measurement of anxiety in patientes undergoing surgery for renal calculus disease. J Adv Nurs. 1990;15:962-70.

Buch $\mathrm{H}$, Vinding $\mathrm{T}$, La Cour M, Nielsen NV. The prevalence and causes of bilateral and unilateral blindness in an elderly urban Danish population. The Copenhagen City Eye Study. Acta Ophthalmol Scand. 2001;79:441-9.

Cabrera CC, Sponholz Jr A. Ansiedade e Insônia. In: Botega NJ. Prática psiquiátrica no hospital geral: interconsulta e emergência. Porto Alegre: Artmed Editora; 2002. p. 251-68.

Campino ACC, Cyrillo DC. Situação de ocupação e renda. In: Lebrão ML. SABE - Saúde, Bem-estar e envelhecimento - O Projeto Sabe no município de São Paulo: uma abordagem inicial. Brasília: Organização Pan-Americana de Saúde; 2003. p. 239-55. 
Carvalho RS. Conduta leiga e assistência médica em pacientes do ProntoSocorro de Oftalmologia do Hospital das Clínicas da Faculdade de Medicina da Universidade de São Paulo [tese]. São Paulo: Faculdade de Medicina, Universidade de São Paulo; 2007.

Centurion V, Carrari MJB, Caballero JC, Lavaca AC. Cirurgia da catarata em portadores de olho único. Rev Bras Oftal. 2000;59(8):572-6.

Chatterjee A, Milton RC, Thyle S. Prevalence and etiology of cataract in Punjab. Br J Ophthalmol. 1982;66:35-42.

Coday MP, Warner MA, Jahrling KV, Rubin P. Acquired Monocular Vision: Functional Consequences From the Patient's Perspective. Ophthal Plast Reconstr Surg. 2002;18(1):56-63.

Colenbrander A. Preservation of Vision or Prevention of Blindness? [editorial]. Am J Ophthalmol. 2002;133(2):263-5.

Cyrillo PI. Aspectos psicológicos relacionados aos portadores de lesões oculares e a utilização de prótese. In: Fonseca EPD. Prótese ocular. São Paulo: CIP; 1987. p. 181-7.

Davidoff LL. Introdução à Psicologia. São Paulo: McGraw-Hill do Brasil; 1983. 
Delgado AMN, Kara-José N. Projetos comunitários em Oftalmologia. In: Kara José N, Delgado AMN, Arieta CEL, Rodrigues MLV, Alves MR. Prevenção da cegueira por catarata. Campinas: Editora da Unicamp; 1996. p. 55-70.

Dicionário de Ciências Sociais. Fundação Getúlio Vargas. Rio de Janeiro: Editora da Fundação Getúlio Vargas; 1986.

Ellwein LB, Kupfer C. Strategic issues in preventing blindness in developing countries. Bull World Health Organ. 1995;73:681-90.

Fagerstrom R. Correlation between psychic and somatic symptoms and vision in aged patients before and after a cataract operation. Psychol Rep. 1991;69:707-21.

Fighera J, Viero EV. Vivências do paciente com relação ao procedimento cirúrgico: fantasias e sentimentos mais presentes. Rev Soc Bras Psicol Hosp. 2005;8(2):51-63.

Fine IH, Packer M, Hoffman RS. New phacoemulsification technologies. $J$ Cataract Refract Surg. 2002;28:1054-60.

Fletcher DC. Low vision: The physician's role in rehabilitation and referral. Geriatrics. 1994;49(5):50-3.

Foggitt PS. Anxiety in cataract surgery: Pilot study. J Cataract Refract Surg. $2001 ; 27: 1651-55$ 
Gieser JP. When Treatment Fails. Caring for Patients With Visual Disability. Arch Ophthalmol. 2004;122:1208-9.

Haddad MAO, Sampaio MW, Kara José N. A adaptação de auxílios para o paciente com baixa visão. In: Sampaio MW, Haddad MAO, Kara José N. Auxílios para baixa visão. São Paulo: Laramara; 2001.

Haynal A, Pasini W. Manual de medicina psicossomática. São Paulo: Masson; 1983.

Hulley SB, Cummings SR. Designing Clinical Research. An epidemiologic approach. Baltimore: Williams e Wilkins; 1988.

International Council of Ophthalmology. Visual Standards: Aspects and Ranges of Vision Loss with Emphasis on Population Surveys. $29^{\text {th }}$ International Congress of Ophtalmology. Sydney, Austrália; April 2002.

Jampel RS. The effect of technology on the indications for cataract surgery. Doc Ophthalmol. 1999;98(1):95-103.

Javitt JC, Brenner MH, Curbow B, Legro MW, Street DA. Outcomes of cataract surgery. Improvement in visual acuity and subjective visual function after surgery in the first, second, and both eyes. Arch Ophthalmol. 1993;111:686-91. 
Johnston M. Anxiety in surgical patients. Psychological Medicine. 1980;10:145-52.

Kara-José N, Arieta CEL. Catarata. In: Rodrigues MLV, Dantas AM. Oftalmologia Clínica. Rio de Janeiro: Cultura Médica; 2001. p. 355-72.

Kara-Júnior N, Arieta CEL. Catarata Senil. In: Kara José N, Almeida GV. Senilidade Ocular. São Paulo: Roca; 2001. p. 99-107.

Kara-José N, Arieta CEL. South American Programme: Brazil. Comm Eye Health. 2000;13:55-6.

Kara-José N, Arieta CEL, Temporini ER, Kang KM, Ambrósio LE. Tratamento cirúrgico da catarata senil: óbices para o paciente. Arq Bras Oftalmol. 1996;59(6):573-7.

Kara-José N, Contreras F, Campos MA, Delgado AM, Mowery RL, Ellwein LB. Screening and surgical intervention results from cataract-free-zone projects in Campinas, Brazil and Chimbote, Peru. Int Ophthalmol. 1990;14:155-64.

Kara-José N, Temporini ER. Cirurgia de catarata: o porquê dos excluídos. Rev. Panam Salud Publica. 1999;6(4):242-8. 
Kara-Júnior N. Cirurgia de catarata: aspectos clínicos e socioeconômicos; Hospital das Clínicas da Faculdade de Medicina da Universidade de São Paulo - 2002 [tese]. São Paulo: Faculdade de Medicina, Universidade de São Paulo; 2003.

Kara-Júnior N, Schellini SA, Silva MRBM, Bruni LF, Almeida AGC. Projeto catarata - qual a sua importância para a comunidade? Arq Bras Oftalmol. 1996;59(5):490-6.

Kara-Júnior N, Temporini ER, Kara-José N. Cataract surgery: expectations of patients assisted during a community project in São Paulo, State of São Paulo, Brazil. Rev Hosp Clín Fac Med S Paulo. 2001;56(6):163-8.

Kelman CD. History of phaco surgery. In: Agarwal S, Agarwal A, Agarwal AG. Phaco, Phakonit \& Laser Phako - A Quest for the Best. El Dorado: Highlights of Ophthalmology; 2002. p. 1-8.

Klein BEK, Klein R, Moss MA. Incident Cataract Surgery - The Beaver Dam Eye Study. Ophthalmology. 1997;104:573-80.

Knight CG, Donnelly MK. Assessing the preoperative adult. Nursing Pract. 1988;13(1):6-17.

Kovács MJ. Deficiência adquirida e qualidade de vida - possibilidades de intervenção psicológica. In: Masini EAFS, Becker E, Pinto EB, Amaral LA, 
Amiralian MLTM, Kovács MJ. Deficiência: Alternativas de Intervenção. São Paulo: Casa do Psicólogo; 1997. p. 95-125.

Kubler-Ross E. Sobre a morte e o morrer. $8^{a}$ ed. São Paulo: Martins Fontes; 1998.

Leaming DV. Practice styles and preferences of American Society of Cataract and Refractive Surgery (ASCRS) members - 1998. Survey. J Cataract Refract Surg. 1999;25:851-9.

Leinhaas MAM, Hedstrom NJ. Low vision: How to assess and treat its emotional impact. Geriatrics. 1994;49(5):53-6.

Lundström M, Fregell G, Sjöblom A. Vision related daily life problems in patients waiting for a cataract extraction. Br J Ophthalmol. 1994;78:608-11.

Marback R, Temporini E, Kara Júnior N. Emotional factors prior to cataract surgery. Clinics. 2007;62(4):433-8.

Marback RF, Temporini ER, Maia Jr OO, Schaefer T, Kara-José Jr N, Kara José N. Atividade ocupacional e catarata senil - opinião de pacientes de hospital universitário. Medicina, Ribeirão Preto. 2005;38(3/4):301-9. 
Minassian DC, Reidy A, Desai P, Farrow S, Vadifis F, Minassian A. The deficit in cataract surgery in England and Wales and the escalating problem of visual impairment: epidemiological modeling of the population dynamics of cataract. Br J Ophthalmol. 2000;84(1):4-8.

Mitsonis Cl, Mitropoulos PA, Dimopoulos NP, Mitsonis MI, Andriotis NM, Gitsa OE, Mitsonis IM. Anxiety and depression in cataract surgery: a pilot study in the elderly. Psychol Rep. 2006;99(1):257-65.

Moraes LO de, Peniche ACG. Ansiedade e mecanismos de coping utilizados por pacientes cirúrgicos ambulatoriais. Rev Esc Enferm USP. 2003;37(3):5462.

Morrell, G. Effect of structured preoperative teaching on anxiety levels of patients scheduled for cataract surgery. Insight. 2001;26(1): 4-9.

Neri-Vela R. Desarrollo histórico de la terapéutica quirúrgica de las cataratas. Rev Mex Oftalmol. 2000;74(6):295-301.

Nijkamp MD, Kenens CA, Dijker AJM, Ruiter RAC, Hiddema F, Nuijts RMMA. Determinants of surgery related anxiety in cataract patients. $\mathrm{Br} \mathrm{J}$ Ophthalmol. $2004 ; 88: 1310-4$ 
Nijkamp MD, Ruiter RAC, Roeling M, Van Der Borne B, Hiddema F, Hendrikse F, Nuijts RMMA. Factors related to fear in patients undergoig cataract surgery: a qualitative study focusing on factors associated with fear and reassurance among patients who need to undergo cataract surgery. Patient Education and Counseling. 2002;47: 265-72.

Obstbaum SA. Utilization, appropriate care, and quality of life for patients with cataracts. Ophthalmology. 2006;113(10):1878-82.

Ohrloff C, Zubcov AA. Comparison of phacoemulsification and planned extracapsular extraction. Ophthalmologica. 1997; 211:8-12.

Oliveira MFP de, Luz PL da. O impacto da cirurgia cardíaca. In: Mello Filho J de. (org). Psicossomática Hoje. Porto Alegre: Artes Médicas Sul; 1992. p. 253-8.

Oliveira RSCS, Temporini ER, Kara José N, Carricondo PC, Kara José A. Perceptions of patients about cataract. Clinics. 2005;60(6):455-60.

Organização Mundial da Saúde. Classificação Internacional de Doenças e Problemas Relacionados à Saúde - Décima Revisão. São Paulo: Edusp; 1993.

Owsley C, McGwin Jr G. Vision Impairment and Driving. Surv Ophthalmol. 1999;43:535-50. 
Padilha MA. Cirurgia de Catarata pela Técnica de Facoemulsificação. Rev Bras Oftalmol. 1982;41(1):21-50.

Pager CK. Expectations and Outcomes in Cataract Surgery. A Prospective Test of 2 Models of Satisfaction. Arch Ophthalmol. 2004;122:1788-92.

Pager CK. Randomised controlled trial of preoperative information to improve satisfaction with cataract surgery. Br J Ophthalmol. 2005;89:10-3.

Papalia DE, Olds SW. Desenvolvimento Humano. Porto Alegre: Artes Médicas Sul; 2000.

Pararajasegaram R. Vision 2020 - The Right to Sight: from strategies to action. Am J Ophthalmol. (Editorial). 1999;128(3):359-60.

Piovesan A, Temporini ER. Pesquisa exploratória: procedimento metodológico para o estudo de fatores humanos no campo da saúde pública. Rev Saúde Pública. 1995;29(4):318-25.

Pomberg ML, Miller KM. Functional Visual Outcomes of Cataract Extraction in Monocular Versus Binocular Patients. Am J Ophthalmol. 2004;138(1):12532.

Ramsay MAE. A Survey of Preoperative fear. Anaesthesia. 1972;27:396-402. 
Rapport CR, Fiori WR, Davis C. Teorias do desenvolvimento. São Paulo: EPU; 1981.

Reidy A, Minassian DC, Desai P, Vafidis G, Joseph J, Farrow S, Connolly A. Increased mortality in women with cataract: a population based follow up of the North London eye study. Br J Ophthalmol. 2002;86:424-8.

Resnikoff S, Pararajasegaram R. Blindness prevention programmes: past, present, and future. Bull. World Health Organ. 2001;79(3):222-6.

Ribeiro JEC, Freitas MM, Araújo GS, Rocha THR. Associação entre aspectos depressivos e déficit visual causado por catarata em pacientes idosos. Arq Bras Oftalmol. 2004;67(5):795-99.

Romano BW. Psicologia e cardiologia: encontros possíveis. São Paulo: Casa do Psicólogo; 2001.

Rosner B. Fundamentals of Biostatistics. Boston: PWS Publishers; 1986.

Roth MC. Atendimento psicológico domiciliar. In: Angerami-Camon VA (Org). Novos Rumos na Psicologia da Saúde. São Paulo: Pioneira Thomson Learning; 2002. p. 125-72.

Ruschel PP, Daut PE, Santos MF. Grupoterapia na redução de complicações pós-operatórias em cirurgia cardíaca. Rev Soc Bras Psicol Hosp. 2000;2(3):57-60. 
Sallum JMF, Maumenee IH. Causas genéticas de visão subnormal. In: Veitzman S. Visão subnormal. Rio de Janeiro: Cultura Médica; São Paulo: CBO/CIBA Vision; 2000. p. 19-32.

Santos FD dos. A aceitação e o enfrentamento da cegueira na idade adulta [dissertação]. São Carlos: Universidade Federal de São Carlos; 2004.

Schwab L. Cataract. In: Schwab L. Eye care in developing nations. San Francisco: The Fundation of the American Academy of Ophthalmology; 1999. p. 21-52.

Seidl EMF, Zannon CMLC. Qualidade de vida e saúde: aspectos conceituais e metodológicos. Cad Saúde Pública. 2004; 20(2):580-88.

Smeltzer SC, Bare BG. Tratado de enfermagem médico-cirúrgica. Rio de Janeiro: Guanabara Koogan; 1994.

Sommer A. Organizing to prevent third world blindness. Am J Ophthalmol. 1989;107(5):544-6.

Sommer A. Public health aspects of ophthalmic disease. Annu Rev Public Health. 1996;17:115-91. 
Steinberg EP, Tielsh JM, Schein OD, Javitt JC, Sharkey P, Cassard SD, Legro MW, Diener-West M, Bass EB, Damiano AM, Steinwachs DM, Sommer A. National study of cataract. Surgery outcomes. Variation in 4month postoperative outcomes as reflected in multiple outcome measures. Ophthalmol. 1994;100:1131-41.

Temporini ER. Pesquisa de oftalmologia em saúde pública: considerações metodológicas sobre fatores humanos. Arq Bras Oftalmol. 1991;54(6):27981.

Temporini ER, Kara-José N. A perda da visão - Estratégias de prevenção. Arq Bras Oftalmol. 2004;67(4):597-601.

Temporini ER, Kara-José N. Cirurgia de catarata: o porquê dos excluídos. Rev Panam Salud Publica/Pan Am J Public Health. 1999;6(4):242-8.

Temporini ER, Kara-José N, Kara-Júnior N. Catarata senil: características e percepções de pacientes atendidos em projeto comunitário de reabilitação visual. Arq Bras Oftalmol. 1997;60(1):79-83.

Temporini ER, Kara Júnior N, Kara-José N, Holzchuh N. Popular beliefs regarding the treatment of senile cataract. Rev Saúde Pública. 2002;36(3):343-9. 
The WHOQOL Group. The World Health Organization Quality Of Life Assessment (WHOQOL): position paper from the World Health Organization. Soc Sci Med. 1995;41:1403-09.

Thylefors B, Négrel AD, Pararajasegaram R, Dadzie KY. Global data on blindness. Bull World Health Organ. 1995;73(1):115-21.

Tielsch JM, Steinberg EP, Cassard SD, Schein OD, Javitt JC, Legro MW, Bass EB, Sharkey P. Preoperative functional expectations and postoperative outcomes among patients undergoing first eye cataract surgery. Arch Ophthalmol. 1995;113(10):1312-8.

Trotter WL, Miller KM. Outcomes of cataract extraction in functionally monocular patients. J Cataract Refract Surg. 2002;28:1348-54.

Uddin I, Kurkuman ARA, Jamil T, Iftikhar R. Pre-operative anxiety in patients admitted for elective surgery in King Saud Hospital, Unaizah, Al-Qassim Kingdom of Saudi Arabia. Pak J Med Sci. 2002;18(4):306-10.

Vargas TVP, Maia EM, Dantas RAS. Patient feelings during the preoperative period for cardiac surgery. Rev Latino-am Enfermagem. 2006; 14(3): 383-8.

Vash CL. Reações à aquisição da deficiência. In: Enfrentando a deficiência: a manifestação, a psicologia, a reabilitação. São Paulo: Pioneira; 1988. p. 323. 
Veitzman S. Fundamentos da Baixa Visão. In: Veitzman S. Visão subnormal. Rio de Janeiro: Cultura Médica; São Paulo: CBO/CIBA Vision; 2000. p. 1-8.

Voon LW, Au Eong KG, Saw SM, Verma D, Laude A. Effect of preoperative counseling on patient fear from the visual experience during phacoemulsification under topical anesthesia: Multicenter randomized clinical trial. J Cataract Refract Surg. 2005;31(10):1966-9.

West S, Sommer A. Prevention of blindness and priorities for the future. Bull World Health Organ. 2001;79(3):244-8.

Westphalen MEA, Carraro TE. Metodologias para a assistência de Enfermagem: teorizações, modelos e subsídios para a prática. Goiânia: Editora AB; 2001.

Williams RA, Brody BL, Thomas RG, Kaplan RM, Brown SI. The psychosocial impact of macular degeneration. Arch Ophthalmol. 1998;116(4):514-20

World Health Organization. The World Health Report 1998 offers an optimistic picture of the 21st century [online]. 1998 [citado Ago 2007]. Disponível em: http://www.who.int/whr/1998/media_centre/press_release/en/index.html. 
World Health Organization. Magnitude and causes of visual impairment. [online]. 2004 [citado Fev 2007]. Disponível em: www.who.int/mediacentre/factsheets/fs282/en/print.html.

Wormald R. Cataract surgery - quantity and quality. $\mathrm{Br} J$ Ophthalmol. 1999;83(8):899-90.

Yorston D, Abiose A. Cataract blindness - the African perspective. Bull World Health Organ. 2001;79(3):257-8.

Zimerman GI. Velhice. Aspectos Biopsicossociais. Porto Alegre: Artes Médicas Sul; 2000. 